\title{
Modeling the Frozen-In Anticyclone in the 2005 Arctic Summer Stratosphere
}

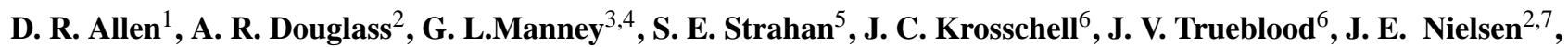 \\ S. Pawson ${ }^{2}$, and Z. Zhu ${ }^{2,7}$ \\ ${ }^{1}$ Naval Research Laboratory, Washington, DC, USA \\ ${ }^{2}$ NASA Goddard Space Flight Center, Greenbelt, MD, USA \\ ${ }^{3}$ Jet Propulsion Laboratory, California Institute of Technology, Pasadena, CA, USA \\ ${ }^{4}$ Department of Physics, New Mexico Institute of Mining and Technology, Socorro, NM, USA \\ ${ }^{5}$ Goddard Earth Science and Technology Center, University of Maryland Baltimore County, Baltimore, MD, USA \\ ${ }^{6}$ Dordt College, Sioux Center, IA, USA \\ ${ }^{7}$ Science Systems and Applications Inc., Lanham, MD, USA
}

Received: 29 December 2010 - Published in Atmos. Chem. Phys. Discuss.: 7 February 2011

Revised: 28 April 2011 - Accepted: 1 May 2011 - Published: 13 May 2011

\begin{abstract}
Immediately following the breakup of the 2005 Arctic spring stratospheric vortex, a tropical air mass, characterized by low potential vorticity (PV) and high nitrous oxide $\left(\mathrm{N}_{2} \mathrm{O}\right)$, was advected poleward and became trapped in the easterly summer polar vortex. This feature, known as a "Frozen-In Anticyclone (FrIAC)", was observed in Earth Observing System (EOS) Aura Microwave Limb Sounder (MLS) data to span the potential temperature range from $\sim 580$ to $1100 \mathrm{~K}$ ( $\sim 25$ to $40 \mathrm{~km}$ altitude) and to persist from late March to late August 2005. This study compares MLS $\mathrm{N}_{2} \mathrm{O}$ observations with simulations from the Global Modeling Initiative (GMI) chemistry and transport model, the GEOS-5/MERRA Replay model, and the Van Leer Icosahedral Triangular Advection (VITA) isentropic transport model to elucidate the processes involved in the lifecycle of the FrIAC, which is here divided into three distinct phases. During the "spin-up phase" (March to early April), strong poleward flow resulted in a tight isolated anticyclonic vortex at $\sim 70-90^{\circ} \mathrm{N}$, marked with elevated $\mathrm{N}_{2} \mathrm{O}$. GMI, Replay, and VITA all reliably simulated the spin-up of the FrIAC, although the GMI and Replay peak $\mathrm{N}_{2} \mathrm{O}$ values were too low. The FrIAC became trapped in the developing summer easterly flow and circulated around the polar region during the "anticyclonic phase" (early April to the end of May). During this phase, the FrIAC crossed directly over the pole between
\end{abstract}

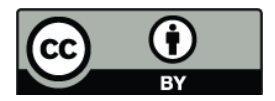

Correspondence to: D. R. Allen (douglas.allen@nrl.navy.mil)
7 and 14 April. The VITA and Replay simulations transported the $\mathrm{N}_{2} \mathrm{O}$ anomaly intact during this crossing, in agreement with MLS, but unrealistic dispersion of the anomaly occurred in the GMI simulation due to excessive numerical mixing of the polar cap. The vortex associated with the FrIAC was apparently resistant to the weak vertical shear during the anticyclonic phase, and it thereby protected the embedded $\mathrm{N}_{2} \mathrm{O}$ anomaly from stretching. The vortex decayed in late May due to diabatic processes, leaving the $\mathrm{N}_{2} \mathrm{O}$ anomaly exposed to horizontal and vertical wind shears during the "shearing phase" (June to August). The observed lifetime of the FrIAC during this phase is consistent with timescales calculated from the ambient horizontal and vertical wind shear. Replay maintained the horizontal structure of the $\mathrm{N}_{2} \mathrm{O}$ anomaly similar to MLS well into August. Isentropic simulations using VITA also captured the horizontal structure of the FrIAC during this phase, but small-scale structures maintained by VITA are problematic and show that important mixing processes are absent from this single-level simulation.

\section{Introduction}

The winter-to-summer transition in the Arctic stratosphere has been examined in numerous observational and modeling studies, and a good general understanding of the processes governing this transition has developed. A consistent finding is that as the winter polar vortex breaks up in the final

Published by Copernicus Publications on behalf of the European Geosciences Union. 
warming, complicated remnants of winter polar vortex air are intermingled with extra-vortex air. These two distinct air masses may remain relatively unmixed in the stratosphere for several months. The winter polar vortex remnants are marked by anomalies in dynamical fields and long-lived chemical tracers. The signature in the dynamical fields (e.g., potential vorticity or potential temperature) tends to decay on a timescale of 1-2 months due to diabatic processes (Hess, 1990, 1991), whereas anomalies in chemical tracers (e.g., low nitrous oxide) can last much longer, persisting even until late August (Orsolini, 2001). These features are said to be "frozen-in" to the summer easterly jet, which is characterized by weak horizontal and vertical shear (Piani and Norton, 2002), thereby allowing complicated structures to remain unmixed for long time periods. The rather quiescent summer polar vortex can be contrasted with the winter polar vortex, in which large-scale irreversible mixing may occur in the presence of upward propagating Rossby waves (McIntyre and Palmer, 1983, 1984). The summer easterlies effectively block the upward propagation of these waves (Charney and Drazin, 1961) and the flow becomes nearly zonally symmetric. Hess (1991) used general circulation model (GCM) simulations of the final warming of 1979 and Nimbus 7 Limb Infrared Monitor of the Stratosphere (LIMS) ozone observations to show gradual homogenization of long-lived chemical tracers with the background over the course of several months. Similar results were obtained with SLIMCAT simulations of $\mathrm{N}_{2} \mathrm{O}$ in the 1998 Arctic spring/summer by Orsolini (2001).

The situation cannot be entirely described by kinematic processes, however. Hess and Holton (1985) and Hess (1991) describe the process whereby the tracer anomalies are initially correlated with the winter polar vortex identified by potential vorticity (PV) anomalies, or "vortices". The vortices, which are resistant to weak wind shear, protect the tracer anomalies from stretching into elongated streaks and mixing irreversibly. The vortices eventually decay due to radiative effects, thereby decorrelating PV from the chemical tracer. The chemical tracer anomalies are then advected passively and eventually homogenize with the ambient air due to shear-enhanced mixing. This two-stage process allows tracer structures to survive the vigorous final warming process and the spin-up of the summer vortex. Waugh and Rong (2002) examined the interannual variability of coherent PV structures that remain following the breakup of the Arctic polar vortex, and they found that their longevity depends critically on the timing of the breakup. In early breakup years (February and March), the vortex remnants survive for around two months, while in late breakup years (late April and May), the vortex remnants disappear quickly. In contrast to the protecting influence of vortices, evanescent planetary waves in the lower stratosphere (below $\sim 25 \mathrm{~km}$ ) can enhance tracer structure in the summer (e.g., Hoppel et al., 1999; Wagner and Bowman, 2000). The tracer patterns in this region are not simply "frozen-in", but have a dynamical source. However, in the middle-to-upper stratosphere (above $\sim 25 \mathrm{~km}$ ), where the feature discussed in this paper resides, these waves are not likely to play a large role.

Most of the work to date has focused on the persistence and eventual homogenization of winter polar vortex remnants in the summer stratosphere. This homogenization process is important for setting up the fall trace gas distribution in the stratosphere (Durry and Hauchecorne, 2005). However, recent work has uncovered convincing evidence for persistent summer polar vortex anomalies of a different type. As explained by Lahoz et al. (2007), an important class of anomalies involve so-called Frozen-In Anticyclones (FrI$\mathrm{ACs}$ ), i.e., long-lived anticyclones originating from low latitudes, in contrast to winter polar vortex remnants, i.e., longlived cyclones originating from high latitudes. The FrIAC was first identified in Aura Microwave Limb Sounder (MLS) data from March-August 2005. Manney et al. (2006, hereinafter M06) describe how anomalies of high $\mathrm{N}_{2} \mathrm{O}$ and low $\mathrm{H}_{2} \mathrm{O}$ were pulled from the tropics to high latitudes and became embedded in an anticyclone that formed in late March. These chemical tracer anomalies persisted throughout the summer, circling westward around the pole until late $\mathrm{Au}-$ gust. M06 searched for FrIAC-like signatures in PV fields for other years and found several possibilities in 1982, 1994, 1997, 2002, and 2003. Global maps of long-lived chemical tracer fields are unavailable for verification except in 2003. Indeed, a second FrIAC event was observed in PV and Michelson Interferometer for Passive Atmospheric Sounding (MIPAS) methane data during the summer of 2003 (Lahoz et al., 2007). This FrIAC developed during the mid-April 2003 final warming and lasted (in the chemical tracer field) until August. Lahoz et al. (2007) examined the FrIAC using polecentered cross-sections along the MIPAS orbit tracks. They identified a W-shaped pattern in the methane field, which was caused by high values at polar latitudes that countered the generally downward and poleward sloping isopleths. Although this pattern was initially established by the poleward advection that resulted in the FrIAC, diabatic processes in the summer may have helped to reinforce the feature.

It has been challenging to produce a credible simulation of the lifecycle of the 2005 FrIAC. M06 used the SLIMCAT chemistry and transport model (CTM) (Chipperfield, 1999) driven by once-daily UK Meteorological Office analyses to study the 2005 FrIAC. SLIMCAT produced the early stages of the FrIAC, but the feature dissipated in late-May and June, two months early. Reverse trajectory calculations also showed unrealistic shredding, suggesting deficiencies in summer high-latitude winds. Since the M06 simulations there have been substantive improvements in wind fields produced by assimilation systems and the use of that information in the CTM framework (e.g., Pawson et al., 2007). The analyses used in this study are produced with much finer horizontal and vertical grids, are available on a higher temporal resolution (6-h rather than 24-h), and were developed with a higher model top $(0.01 \mathrm{hPa}$ rather than $0.1 \mathrm{hPa})$ than what 
was used in M06. This paper presents 2-D (horizontal) and 3-D simulations of the 2005 event, both to enhance our understanding of the physical nature of the FrIAC as well as to test current modeling capability of the summer polar circulation. The FrIAC provides an excellent natural experiment of a robust, long-lived coherent tracer structure that is both interesting and challenging to model. Section 2 describes the observational data (dynamical fields and chemical tracers) used in this study. Section 3 details the simulations used to reproduce the FrIAC. Section 4 presents the results, partitioning the FrIAC lifecycle into three phases: spin-up phase (March to early April); anticyclonic phase (early April to May); and shearing phase (June to August). Section 5 provides a summary and conclusions.

\section{Observational data}

\subsection{Meteorological data}

The meteorological dataset used for the dynamical fields in this study is the Goddard Earth Observing System Version 5.10 (GEOS-5) analysis from NASA's Global Modeling and Assimilation Office (GMAO), described by Reinecker et al. (2008). GEOS-5 uses the Gridpoint Statistical Analysis method of Wu et al. (2002), a 3-D-Variational system, and a six-hour analysis window. The interface between the observations and the Global Circulation Model (GCM) is performed using the incremental analysis update (IAU) approach (Bloom et al., 1996). GEOS-5 analyses are provided on 72 model levels from the surface to $0.01 \mathrm{hPa}$ $(75 \mathrm{~km})$, on a $1 / 2^{\circ}$ latitude by $2 / 3^{\circ}$ longitude grid. The GEOS-5 PV and geopotential height are interpolated vertically to six isentropic surfaces for use in this study $(580,650$, $740,850,960$, and $1100 \mathrm{~K})$. The Modern Era RetrospectiveAnalysis for Research and Applications (MERRA) reanalysis is also used for the Replay simulation described in Sect. 2.3. MERRA is a reanalysis from 1979 to the present, which uses the GEOS-5 data assimilation system (Version 5.20) throughout, providing a consistent analysis that includes online bias correction for satellite radiance observations (see http://gmao.gsfc.nasa.gov/merra for details).

\subsection{Microwave Limb Sounder data}

The EOS Aura MLS measures millimeter- and submillimeter-wavelength thermal emission from the limb of Earth's atmosphere. Detailed information on the measurement technique and the MLS instrument on the EOS Aura satellite are given in Waters et al. (2006). The Aura MLS fields-of-view point in the direction of orbital motion and vertically scan the limb in the orbit plane, leading to data coverage from $82^{\circ} \mathrm{S}$ to $82^{\circ} \mathrm{N}$ latitude on every orbit. Vertical profiles are measured every $165 \mathrm{~km}$ along the suborbital track and have a horizontal resolution of $\sim 200-300 \mathrm{~km}$ along-track and $\sim 39 \mathrm{~km}$ across track. We use version $2.2 \mathrm{~N}_{2} \mathrm{O}$; validation of which is discussed by Lambert et al. (2007). Vertical resolution of the $\mathrm{N}_{2} \mathrm{O}$ data is $\sim 4 \mathrm{~km}$ for the region of interest in this study (approximately 30-3 hPa). For maps, MLS data are gridded using spatially weighted averages of each day's data in the region around each gridpoint on a $2.0^{\circ}$ latitude by $5.0^{\circ}$ longitude grid. Data values in the region not observed by MLS (polewards of $82^{\circ} \mathrm{N}$ ) are calculated by interpolating over the polar region from neighboring grids. This is necessary for initializing the Van leer Icosahedral Triangular Advection (VITA) model with complete global maps.

\section{Models}

\subsection{Three-dimensional chemistry and transport models}

Results are presented from two different three-dimensional simulations based on the Global Modeling Initiative (GMI) Chemistry and Transport Model (hereinafter, GMI) and the GEOS-5/MERRA Replay model (hereinafter, Replay). Both simulations use meteorological fields derived from GEOS-5 analyses (Rienecker et al., 2008) to constrain transport, but adopt different modeling approaches.

The GMI advection core uses a modified version of the flux form semi-Lagrangian numerical transport scheme (Lin and Rood, 1996). The GMI CTM is an offline computation that reads meteorological fields, including temperatures, winds and sub-grid transport variables such as cloud-mass fluxes and turbulence parameters, from the GEOS-5 MERRA analyses. These meteorological fields are updated every three hours. The "G5Aura" simulation that is presented in this study uses the "Combo" chemical mechanism. "Combo" combines the stratospheric chemistry described in Douglass et al. (2004) with tropospheric chemistry from the Harvard GEOS-CHEM model (Bey et al., 2001), as discussed in Strahan et al. (2007). The horizontal resolution is $2.0^{\circ}$ latitude by $2.5^{\circ}$ longitude, while the vertical resolution in the region of interest for this study (approximately $30-3 \mathrm{hPa}$ ) is $\sim 1.1-$ $1.5 \mathrm{~km}$.

The Replay simulation also uses the Combo chemistry mechanism, but it is implemented on-line in the GEOS-5 General Circulation Model using the advection core of Lin (2004), a newer version of the flux-form semi-Lagrangian numerical transport than used in GMI, that adopts a quasimaterial vertical coordinate in the transport code. One noticeable difference that impacts this study is that the GEOS5 advection core has an improved implementation of polar transport compared with the current GMI transport scheme via use of a smaller polar mixing cap (details are provided in Sect. 4.3). A practical advantage of Replay over the CTM simulation is that the sub-grid transport fields are computed internally by the model, so the Replay simulation only uses the meteorological fields (surface pressure, temperature, winds, and moisture) as input. The approach is conceptually 
identical to the "MATCH" technique of Rasch et al. (1997), where the meteorological fields from the GCM are overwritten every six hours with fields from the analysis system. Similar simulations with GEOS-4 are described in Pawson et al. (2007), for which six-hour averages of the meteorological fields were shown to result in improved simulations over snapshots. In GEOS-5, the analysis technique uses incremental analysis updates (Bloom et al., 1996) that lead to smoother time series, without the spurious oscillations shown in Pawson et al. (2007). This allows the use of instantaneous six-hourly fields in GEOS-5 Replays. An additional change is that the six-hour forecasts (background) fields instead of the assimilated fields are used in the simulation described in this work. Sub-grid transport is computed at the same frequency (every $30 \mathrm{~min}$ ) as the physics computations in the GEOS-5 GCM.

\subsection{Van Leer Icosahedral Triangular Advection (VITA) 2-D Isentropic Transport Model}

High-resolution simulations of the FrIAC were made with the Van leer Icosahedral Triangular Advection (VITA) model, which solves the advection equation for a passive tracer on the sphere using a finite-volume technique on a triangular grid (Allen and Nakamura, 2001, 2003). The finitevolume approach with a triangular grid is explained in Putti et al. (1990) for equilateral triangles. Our approach differs from Putti et al. (1990) in two significant ways. First, since it is not possible to cover the sphere with perfectly equilateral triangles, the VITA grid uses non-equilateral triangles. Defining the triangle center for non-equilateral triangles is ambiguous. We decided to use the circumcenter, defined as the intersection of the perpendicular bisectors of the sides. This definition allows the center-to-side differences to be easily calculated in determining the gradients. Attempts were made to limit the variation in triangular size by shifting the locations of the nodes upon iteration. The current configuration using 983040 triangles has a mean center-to-side distance of $9996 \mathrm{~m}$, with a minimum distance of $6,147 \mathrm{~m} \mathrm{(38 \%}$ smaller) and maximum distance of 11,814 $\mathrm{m}$ (18\% larger). The nominal resolution is defined as twice the mean centerto-side distance or $\sim 20 \mathrm{~km}$. The second difference is that the limiting function used in Putti et al. (1990), the so-called "minmod" function, was replaced with the "superbee" function (Roe, 1985). The superbee limiter provides less numerical diffusion, allowing sharper tracer gradients to be maintained (Sweby, 1984). The VITA code is driven by offline winds (GEOS Version 5.10) at 24-h increments interpolated linearly in time and space to isentropic surfaces and to the circumcenter of each triangle.

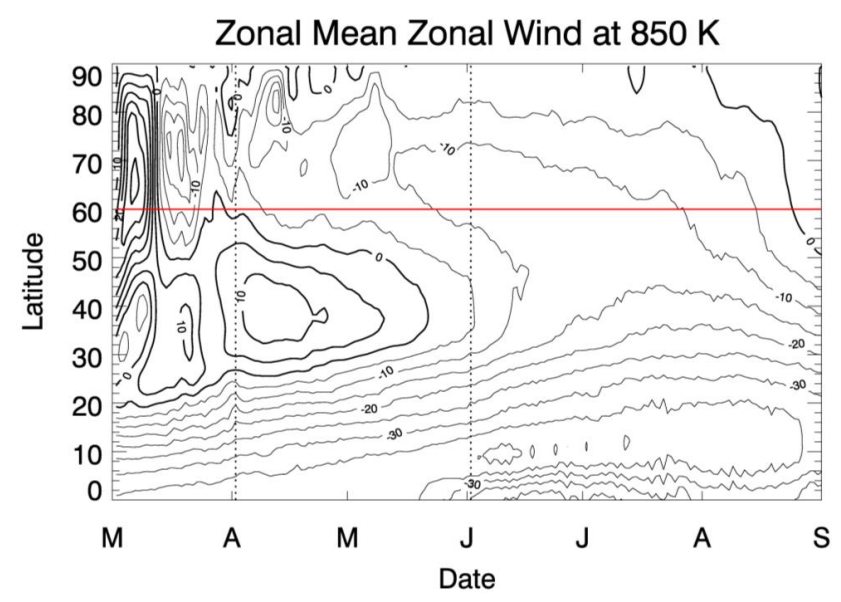

Fig. 1. Zonal mean zonal wind at $850 \mathrm{~K}$ potential temperature for March-August 2005. Vertical dotted lines indicate transitions between the three phases of the FrIAC (see text for details), while the red line marks $60^{\circ} \mathrm{N}$ latitude.

\section{Modeling the FrIAC}

\subsection{Overview of the 2005 Spring/Summer}

The winter-to-summer transition in the Arctic polar stratosphere is characterized by a reversal of the mean zonal wind from westerly to easterly. This reversal occurs during the final warming, with the precise timing varying from year to year (e.g., Waugh and Rong, 2002). Figure 1 shows the zonal mean zonal wind at $850 \mathrm{~K}$ potential temperature $(\sim 32 \mathrm{~km})$ for March-August 2005 to provide an overview of this period. The winter polar vortex is centered at around $65^{\circ} \mathrm{N}$ at the beginning of March and the zonal wind is increasing following a minor warming in late February. A major warming occurs around March 10-15, with a reversal to easterlies poleward of $\sim 50^{\circ} \mathrm{N}$. The easterlies decelerate in late March and return briefly to westerlies at $60^{\circ} \mathrm{N}$ before starting a gradual easterly acceleration in April and May. The winds remain fairly steady during June and July at this latitude, with peak values of around $12 \mathrm{~m} \mathrm{~s}^{-1}$. The reversal to westerlies occurs near the pole on 1 August and transitions steadily southward to reach $50^{\circ} \mathrm{N}$ by 1 September. Although we show only $850 \mathrm{~K}$ level, the 2005 FrIAC extends from $\sim 580$ to $1100 \mathrm{~K}$. The zonal wind evolution at all levels throughout this height range is very similar to that shown here in terms of the timing of the wind reversals.

The vertical lines drawn on Fig. 1 relate to the three phases of the FrIAC described in the subsequent sections. The first phase involves the spin-up of the FrIAC during March and early April. The second phase refers to the period where the FrIAC can be identified by a coherent anticyclone (early April-late May). The third phase (June-August) marks the time when the chemical tracer signature of the FrIAC is gradually sheared by the background wind. 

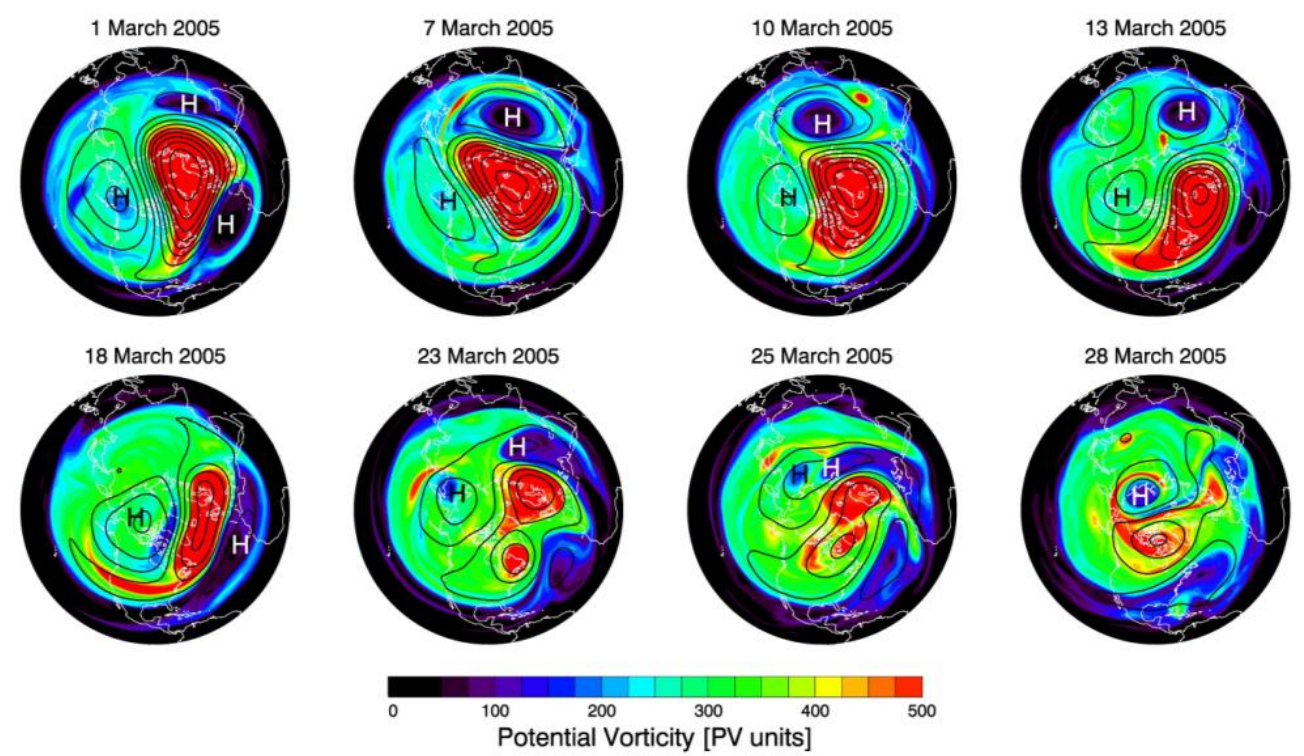

Fig. 2. Northern Hemisphere Ertel potential vorticity at $850 \mathrm{~K}$ potential temperature for 1, 7, 10, 13, 18, 23, 25, and $28 \mathrm{March} 2005$. PV units are used, where $1 \mathrm{PVU}=1.0 \times 10^{-6} \mathrm{~m}^{2} \mathrm{~s}^{-1} \mathrm{~K} \mathrm{~kg}^{-1}$. Red (blue) indicates high (low) values of PV. Black lines indicate $10 \mathrm{hPa}$ geopotential height at 250-m contour intervals. The black " $\mathrm{H}$ " marks the location of the Aleutian anticyclone and the white " $\mathrm{H}$ "s mark the locations of other anticyclones.

\subsection{Modeling the spin-up phase: March-early April}

We frst examine the spin-up of the 2005 FrIAC using PV and geopotential height in order to highlight dynamical processes. Figure 2 shows Northern Hemisphere PV contours at $850 \mathrm{~K}$, overlaid with $10 \mathrm{hPa}$ geopotential height (black lines), for select days during March 2005. On 1 March, the winter polar vortex (identified by high PV) is somewhat elongated and displaced from the pole due to a strong Aleutian high (identified by black " $\mathrm{H}$ "). There are two additional anticyclonic centers (identified by white "H"s) visible on this day with closed height contours and low PV; one is off the coast of western Africa and the other is over Asia. The Asian high remains stationary over the next several days, while the African high moves eastward (counter clockwise) and merges with the Asian high, resulting in a strong Asian high on 7 March. During this time, the Aleutian high weakens and the vortex moves back towards the pole. The Asian high travels slowly eastward over the next three days and is approaching the Aleutian high on 10 March. Together with the winter polar vortex and anticyclones, the stratosphere develops a strong wave 2 pattern in the geopotential height on 13 March, characteristic of the preconditioning phase of many major sudden warmings (Andrews et al., 1987).

From 13-18 March, the two anticyclones merge into one large anticyclone. While this is occurring, a tongue of low latitude, low PV air is advected along the poleward flank of the now highly elongated winter polar vortex. This low PV air circulates around the Aleutian high in a clockwise direction and becomes entrained into the Aleutian high by 23
March. The winter polar vortex breaks into three distinct regions by 23 March (identified by lobes of high PV), while another anticyclone is developing over Asia (identified by white "H"), immediately eastward of the largest winter polar vortex remnant. From 23-25 March, this developing anticyclone moves eastward and poleward and merges with the Aleutian high, similar to the events of 13-18 March. A large tongue of low PV air stretches across northern Asia on 25 March, indicating significant poleward transport. A portion of this tongue is entrained into the Aleutian high so that by $28 \mathrm{March}$, the newly merged anticyclone is a coherent entity at high latitudes that is vying for the polar position with the weakening main polar vortex remnants. During this time, the extratropical wave motion is subsiding and the FrIAC becomes a well-established feature in the polar circulation (identified by white " $\mathrm{H}$ " on $28 \mathrm{March}$ ).

Figure 3 illustrates the vertical extent of the FrIAC a week later, on 4 April, using PV maps on multiple isentropic surfaces. Coherent low PV anomalies are visible from $580 \mathrm{~K}$ to $1100 \mathrm{~K}(\sim 25-40 \mathrm{~km})$, with correlated closed height contours indicating anticyclonic circulation. At $1300 \mathrm{~K}$ there appears to be only a weak indication of a low PV anomaly associated with one closed height contour. The FrIAC is observed to be vertically upright at this stage with a horizontal width of approximately 20 degrees latitude $(\sim 2000 \mathrm{~km})$ across. So at this point, the FrIAC can be described as a coherent vortex $\sim 15 \mathrm{~km}$ high and $\sim 2000 \mathrm{~km}$ wide embedded in the stratospheric flow. Later we will show that the FrIAC remains vertically upright throughout April and most of May. 

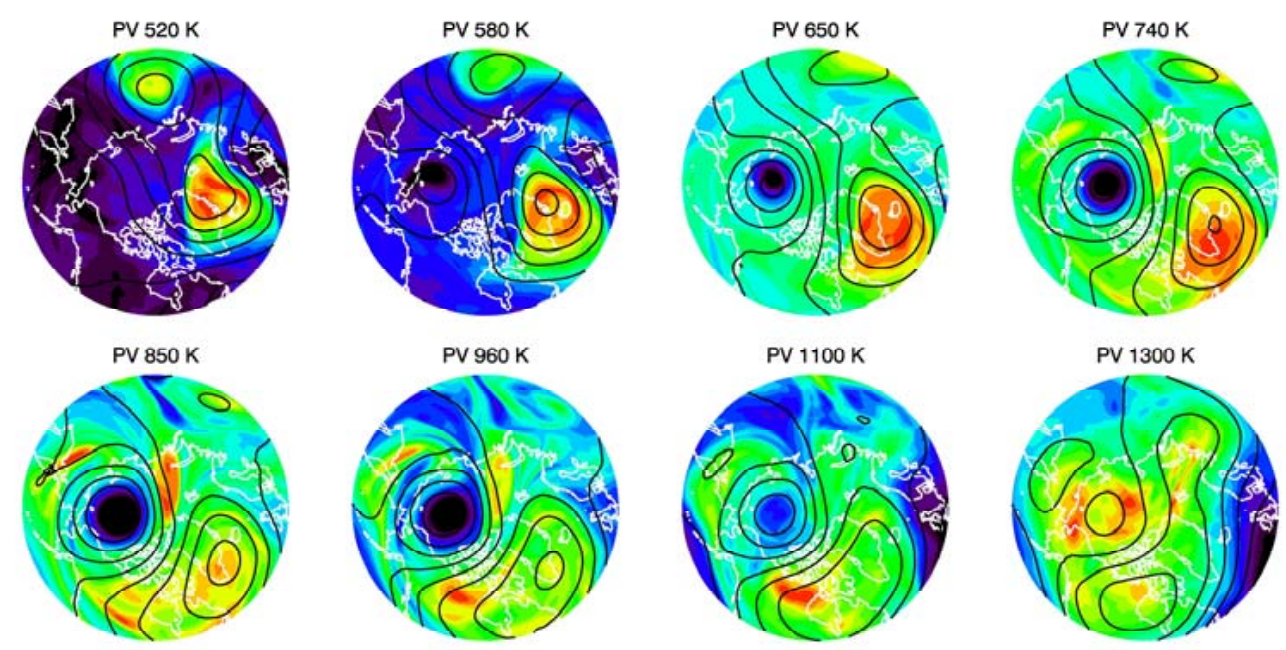

Fig. 3. Ertel potential vorticity at eight potential temperature levels $(520,580,650,740,850,960,1100$, and $1300 \mathrm{~K})$ from $50-90^{\circ} \mathrm{N}$ on 4 April 2005 (Greenwich Meridian is on the right side). Colors are scaled to the range of PV values for the given level, with red (blue) indicating high (low) PV. Black lines show $10 \mathrm{hPa}$ geopotential height at 100-m contour intervals.

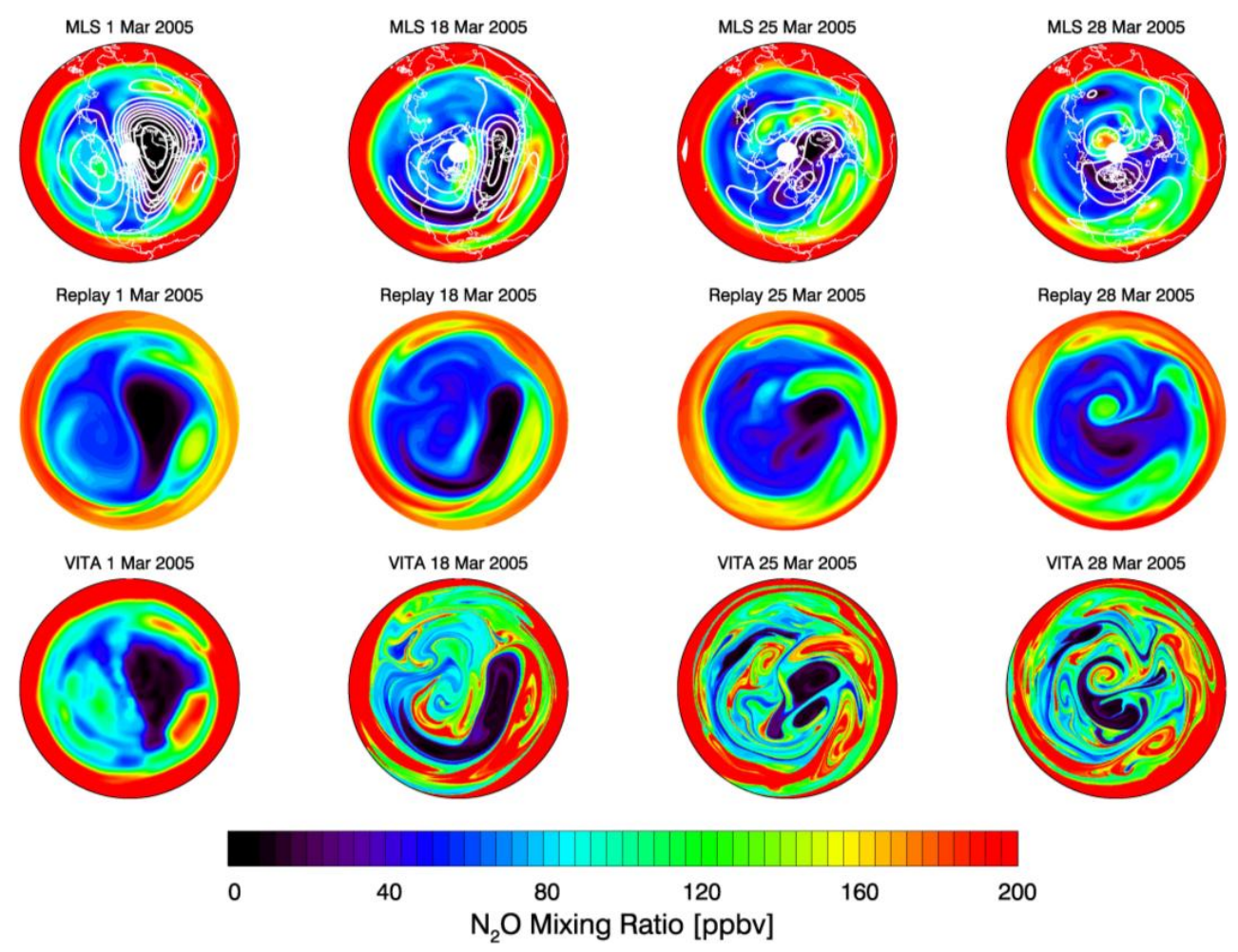

Fig. 4. Northern Hemisphere EOS Aura MLS $\mathrm{N}_{2} \mathrm{O}$ mixing ratio at $850 \mathrm{~K}$ for $1,18,25$, and 28 March 2005 overlaid with contours of $10 \mathrm{hPa}$ geopotential height at 250-m intervals (first row). Red (blue) indicates high (low) $\mathrm{N}_{2} \mathrm{O}$ values. Replay $\mathrm{N}_{2} \mathrm{O}$ simulations for the same days (second row). VITA $\mathrm{N}_{2} \mathrm{O}$ simulations initialized on 1 March 2005 (third row).

Given the characterization of the dynamical anomalies involved with the FrIAC, we now examine observations and simulations of the chemical tracer anomalies that accompany the spin-up phase. As shown by M06, MLS $\mathrm{N}_{2} \mathrm{O}$,
$\mathrm{H}_{2} \mathrm{O}$ and $\mathrm{O}_{3}$ anomalies marked the location of the FrIAC. We focus here on $\mathrm{N}_{2} \mathrm{O}$, since the GMI and Replay simulations do not have $\mathrm{H}_{2} \mathrm{O}$ as a prognostic variable in the stratosphere and since the $\mathrm{O}_{3}$ anomaly decays in early April due 
to photochemistry. Figure 4 shows the MLS $\mathrm{N}_{2} \mathrm{O}$ evolution at $850 \mathrm{~K}$, for March 2005, along with Replay and VITA simulations. The VITA simulations were initialized on 1 March using gridded MLS $\mathrm{N}_{2} \mathrm{O}$ data and provide additional interpretation of high-resolution features that are not resolvable by MLS, GMI, or Replay. Fine-scale filamentary structures have been observed to cascade below the resolution of most Eulerian transport models, down to a few kilometers in the horizontal (e.g., Flentje and Kiemle, 2003). The horizontal scale of the VITA grid $(\sim 20 \mathrm{~km})$ is larger than these observed filaments, suggesting that features observed in VITA should be realistic. However, given that VITA is an isentropic model, it neglects diabatic effects and vertical mixing processes and therefore some filaments, particularly in regions of large vertical shear, may last longer than in the real atmosphere (discussed further in Sect. 4.4).

The MLS data on 1 March show regions of high $\mathrm{N}_{2} \mathrm{O}$ coinciding with the anticyclonic centers over Asia and off the coast of Africa, indicating air of tropical origin. The MLS data also show evidence of high $\mathrm{N}_{2} \mathrm{O}$ tropical air that had previously been entrained into the Aleutian high, a well-known process (Harvey et al., 1999). As the Asian and Aleutian anticyclones merge around 13-18 March, the winter polar vortex become comma-shaped, with the "head" of the comma poised for poleward advection of tropical air. The result of this advection is visible on 18 March, when a long ribbon of high $\mathrm{N}_{2} \mathrm{O}$ air is drawn along the poleward flank of the now highly elongated vortex. Some of this high $\mathrm{N}_{2} \mathrm{O}$ air is eventually entrained into the Aleutian high, which has now consolidated with the Asian high into one large anticyclone that by this time is centered close to the pole.

On 25 March, both MLS and Replay show a large tongue of high $\mathrm{N}_{2} \mathrm{O}$ air stretching across northern Asia. The VITA simulation shows much finer detailed structure as this tongue merges with elevated $\mathrm{N}_{2} \mathrm{O}$ in the Aleutian high. The VITA simulation on 25 March shows complicated swaths of high $\mathrm{N}_{2} \mathrm{O}$ air throughout the extratropical region, interwoven with low- $\mathrm{N}_{2} \mathrm{O}$ air that originated in the winter polar vortex. By 28 March, the newly merged anticyclone is vying for the polar position with the weakening main polar vortex remnant. These two features are clearly marked by high/low $\mathrm{N}_{2} \mathrm{O}$ values. The VITA simulation on 28 March has generally higher background $\mathrm{N}_{2} \mathrm{O}$ values than MLS or Replay. This may be due partly to the VITA simulation being isentropic, while the diabatic circulation will pull down lower $\mathrm{N}_{2} \mathrm{O}$ air over the course of the month. However, the high resolution run does show numerous stripes of low $\mathrm{N}_{2} \mathrm{O}$ interwoven with high. The smoothing resulting from the retrieval and gridding could account for the more uniform structure in the MLS data.

To examine this in more detail, Fig. 5 provides slices through two Aura MLS orbit tracks that cross the center of the FrIAC on 28 March at $850 \mathrm{~K}$. The locations of these tracks are indicated by the white lines overlaid on polar plots of VITA and Replay $\mathrm{N}_{2} \mathrm{O}$. The VITA and Replay $\mathrm{N}_{2} \mathrm{O}$ are interpolated linearly in time and space to the locations of the MLS observations for direct comparison. "Orbit 1" extends from left-to-right across the polar plots, starting in the tropics and passing through the midlatitude "surf zone" in which VITA shows complicated swaths of high and low $\mathrm{N}_{2} \mathrm{O}$. The line plots across this track (bottom left of Fig. 5) indicate higher variability of VITA $\mathrm{N}_{2} \mathrm{O}$ in this region (profiles 25-45) compared with MLS and Replay. This is expected, since the VITA simulations are at $20 \mathrm{~km}$ resolution, while MLS data have a horizontal resolution of approximately $200-300 \mathrm{~km}$ along-track and the meridional resolution for the Replay simulation is 2 degrees latitude $(\sim 220 \mathrm{~km})$. The Orbit 1 track crosses the polar vortex around profile 45, indicated by the low $\mathrm{N}_{2} \mathrm{O}$ values in the line plots, before encountering the FrIAC from profiles 50-65. The peak value of the FrIAC observed by MLS ( 200 parts per billion by volume, ppbv) is similar in the VITA simulation, but is lower in Replay ( $135 \mathrm{ppbv})$. As we will show, this is due to a low bias in the tropical $\mathrm{N}_{2} \mathrm{O}$ in the Replay simulations. From profiles 70-80 MLS encounters a second region of elevated $\mathrm{N}_{2} \mathrm{O}$ followed by a remnant of the winter polar vortex. These are seen as high and low $\mathrm{N}_{2} \mathrm{O}$ anomalies centered around profiles 70 and 85 , respectively. The track ends in the high- $\mathrm{N}_{2} \mathrm{O}$ tropical region.

The second track (Orbit 12) starts in the tropics and crosses the main remnant of the winter polar vortex (profiles 40-60) before encountering the FrIAC (profiles 60-75). VITA shows more complicated structure in the FrIAC due to the swirling contours of high/low $\mathrm{N}_{2} \mathrm{O}$, which are not evident in either MLS or Replay. After leaving the FrIAC this orbit passes through alternating regions of low and high $\mathrm{N}_{2} \mathrm{O}$ originating from the winter polar vortex and tropics, respectively (profiles 75-100). The Replay and VITA simulations for this region are in qualitative agreement with the MLS data, although VITA shows a large spike at profile 85 not visible in MLS.

To examine the vertical structure along these tracks, MLS and Replay "curtain plots" are provided in Fig. 6. In Orbit 1 the FrIAC spans profiles 50-65 with elevated MLS $\mathrm{N}_{2} \mathrm{O}$ extending from around $580-1100 \mathrm{~K}$, consistent with the vertical extent of the PV anomaly. Replay shows similar location and extent of the FrIAC, although peak values are too low. Replay also captures the structure of the tilting winter polar vortex remnant from profiles 70-100. The curtain plots for the second track show similar vertical extent and magnitude of the FrIAC as in the first track, with the Replay again having similar morphology of the main features observed in MLS.

Another view showing the vertical extent of the FrIAC is provided via polar plots of $\mathrm{N}_{2} \mathrm{O}$ on 4 April from $580-1100 \mathrm{~K}$ (Fig. 7), which can be compared with the PV plots in Fig. 3. $\mathrm{N}_{2} \mathrm{O}$ anomalies exist in the MLS data at all levels, although at $1100 \mathrm{~K}$ the data appear rather noisy. Neither GMI nor Replay has a coherent positive anomaly at $580 \mathrm{~K}$ and $1100 \mathrm{~K}$, but both show coherent anomalies from 650-960 K. The 

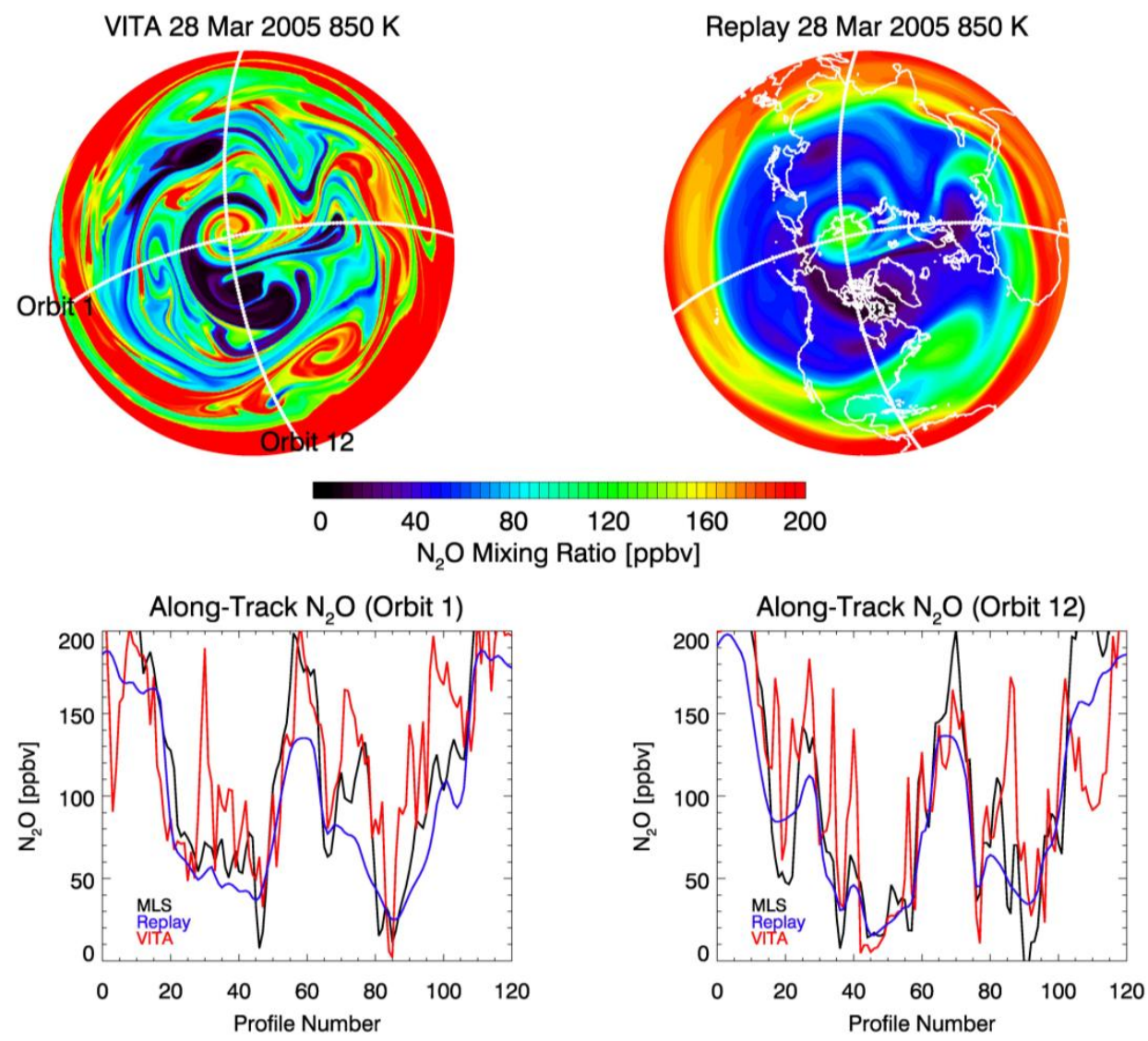

Fig. 5. Top row: Northern Hemisphere VITA (left) and Replay (right) $\mathrm{N}_{2} \mathrm{O}$ at $850 \mathrm{~K}$ on 28 March 2005. Red (blue) indicates high (low) $\mathrm{N}_{2} \mathrm{O}$ values. Overlaid are two EOS Aura MLS orbit tracks for this day. Second row: MLS (black), Replay (blue), and VITA (red) $\mathrm{N}_{2} \mathrm{O}$ at $850 \mathrm{~K}$ along the selected orbit tracks. The profiles start at the locations of the orbit labels in the upper left panel. Replay and VITA data are interpolated linearly in space and time to the MLS data points.

position and extent of the anomalies agree with the MLS data, but in each case the maximum $\mathrm{N}_{2} \mathrm{O}$ values in GMI and Replay are too low. This is due to a low bias in the tropical zonal mean $\mathrm{N}_{2} \mathrm{O}$ in GMI and Replay, with Replay showing the largest bias of up to $\sim 40 \mathrm{ppbv}$ in this range. Since the FrIAC develops from relatively unmixed tropical air, we would expect that the peak GMI and Replay values will be low. The VITA simulations in Fig. 7 that are initialized with MLS observations capture the location and structure of the $\mathrm{N}_{2} \mathrm{O}$ anomalies, suggesting the spin-up process mainly involves isentropic flow. Complicated swirling structure is observed at $960 \mathrm{~K}$, highlighting the anticyclonic circulation of the FrIAC. However, large background $\mathrm{N}_{2} \mathrm{O}$ values that occur at 960 and $1100 \mathrm{~K}$ are unrealistic and may be due to neglect of diabatic processes in VITA. The success of the simulations in reproducing many of the fine-scale features in the polar stratosphere attests to the high quality of both the implemented transport scheme as well as the assimilated wind fields from GEOS-5 and MERRA.

\subsection{Modeling the Anticyclonic phase: early April-May}

The second phase of the FrIAC is characterized by the existence of a coherent anticyclone that meanders about the pole for approximately two months. The FrIAC during this phase can still be identified by anomalously low PV and closed geopotential height contours. Figure 8 shows PV and geopotential height at $850 \mathrm{~K}$ for select days in April and May 2005. Immediately following the spin-up phase, the FrIAC takes a path directly across the pole, as seen in the maps for 1, 7, and 14 April, where the PV anomaly moves from left to right across the map (examined in more detail below). Following the polar crossing, from 14 April-5 May, the FrIAC travels westward completely around the pole; on 28 April it is centered near $180^{\circ}$ longitude and by 5 May moves to the Greenwich Meridian, similar to 14 April. By 5 May, the PV anomaly has noticeably weakened. In addition, the winter polar vortex remnants, marked by high PV, have weakened as well, as expected due to radiative processes (Hess, 1991). From 5-9 May the FrIAC makes a second polar-crossing (this time from right to left across the 

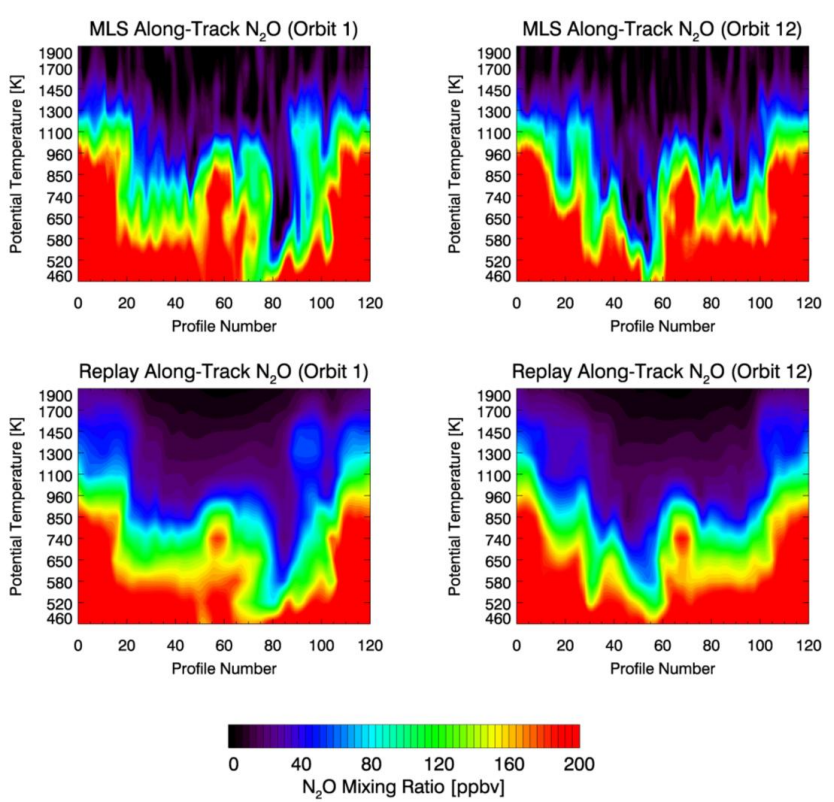

Fig. 6. MLS and Replay curtain plots (along-track cross-section as function of pressure and profile number) for the two orbits from 28 March 2005 (see Fig. 5). Red (blue) indicates high (low) $\mathrm{N}_{2} \mathrm{O}$ values.

maps on Fig. 8) before continuing steady westward progression around the pole. On 15 May, the PV anomaly is very weak, and by 30 May has completely disappeared. The PV anomaly therefore lasted approximately two months after the winter polar vortex breakup in late March, consistent with expectations for a late-March breakup of the northern winter vortex (Waugh and Rong, 2002).

Figure 9 presents the MLS, Replay, and VITA $\mathrm{N}_{2} \mathrm{O}$ evolution during this period at $850 \mathrm{~K}$. For this phase, VITA was reinitialized on 1 April 2005 with MLS data. This reinitialization allows a better direct comparison for this period by removing much of the fine-scale structure that was generated in VITA during the polar vortex breakup (see Fig. 5). Also, this re-initialization removes any biases that develop due to lack of vertical motion in VITA. The maps for 1 April show high $\mathrm{N}_{2} \mathrm{O}$ air in the anticyclonic vortex. From this point on we will continue to refer to the region of high $\mathrm{N}_{2} \mathrm{O}$ as the Frozen-In Anticyclone (FrIAC), although as seen in Fig. 8, the feature is not always identified by local anticyclonic circulation (identified by closed PV or height contours surrounding the FrIAC). From 1-7 April, the FrIAC moves slightly eastward and poleward, and from 7-14 April, the FrIAC moves directly across the pole and becomes centered over northern Greenland. This episode provides a useful test of the numerical representation of cross-polar flow, which has posed problems for global models based on regular latitude/longitude grids (Williamson, 2007). Early versions of GMI imposed a well-mixed polar cap in order to dampen effects of noisy assimilated wind fields at the pole and keep the transport code stable (Allen et al., 1991). This approximation uniformly smooths the constituent mixing ratios over the area of the polar cap, thereby introducing an artificial diffusive transport. Although present meteorological fields are far less noisy than those available to Allen et al. (1991), in GMI the polar cap still extends from $87^{\circ}$ to the pole and is $6^{\circ}$ $(\sim 660 \mathrm{~km})$ across. The Replay transport scheme applies the polar cap only over one grid cell, extending from $89^{\circ}$ to the pole, thereby decreasing the area of the cap by a factor of 9 , substantially reducing the artificial diffusion.

The MLS data and simulations from GMI, Replay, and VITA for the cross-polar flow at $740 \mathrm{~K}$ are provided in Fig. 10. On 8 April the $\mathrm{N}_{2} \mathrm{O}$ anomaly starts to encounter the polar cap region (identified by black circles in GMI and Replay). A small "bite-out" of the $\mathrm{N}_{2} \mathrm{O}$ maximum can be seen at the pole on this day in the GMI simulation. Two days later, a large portion of the GMI $\mathrm{N}_{2} \mathrm{O}$ anomaly has been reduced by the artificial diffusion, and by 12 April the red contours, indicating mixing ratios over $\sim 150 \mathrm{ppbv}$ have disappeared completely. The peak mixing ratio during this period decreases by $22 \%$ from 172 to 133 ppbv in the GMI simulation. The Replay simulation, on the other hand, shows a nearly constant $\mathrm{N}_{2} \mathrm{O}$ peak as the FrIAC crosses the pole. Only a very slight drop $(\sim 1 \%)$ is observed in this run, consistent with the nearly constant peak in the MLS data. In hindsight, these results are to be expected, since implementation with a polar cap of $660 \mathrm{~km}$ is unable to resolve a feature $\sim 2000 \mathrm{~km}$ across. The Replay polar cap is much smaller relative to the size of the FrIAC and therefore the artificial smoothing is applied over a much smaller area. In the remainder of the paper we focus on the Replay simulation, since the FrIAC is significantly "washed out" in the GMI simulation after this event. Note that the VITA simulation advects the FrIAC over the pole undiminished as there is no "pole-problem" with the triangular grid.

During this time the easterly summer jet is accelerating (see Fig. 1), so that around 14 April the FrIAC starts its westward march around the pole, reaching $180^{\circ} \mathrm{E}$ longitude by 28 April and back near the Greenwich Meridian on 5 May (Fig. 9). Even though the feature is advected westward around the pole, it still exhibits local anticyclonic rotation (see closed height contours on 5 May). After the second polar crossing on 5-9 May, the FrIAC continues to circle the pole with a rotation period of approximately 10-15 days, maintaining a central position at latitude around $70-80^{\circ} \mathrm{N}$.

On 15 May (not shown) there is still a clear correspondence between the location of the geopotential height maximum and the highest $\mathrm{N}_{2} \mathrm{O}$ values. From 15-30 May, the geopotential height and $\mathrm{N}_{2} \mathrm{O}$ contours decouple, so that the FrIAC is no longer identified by local anticyclonic rotation, but is rather embedded in large-scale anticyclonic flow centered at the pole. Starting at this point, the air marked by high $\mathrm{N}_{2} \mathrm{O}$ mixing ratios is advected passively by the circumpolar jet. The immediate result is that a large streamer of high $\mathrm{N}_{2} \mathrm{O}$ air emerges from the main core of the FrIAC around 15 May. 

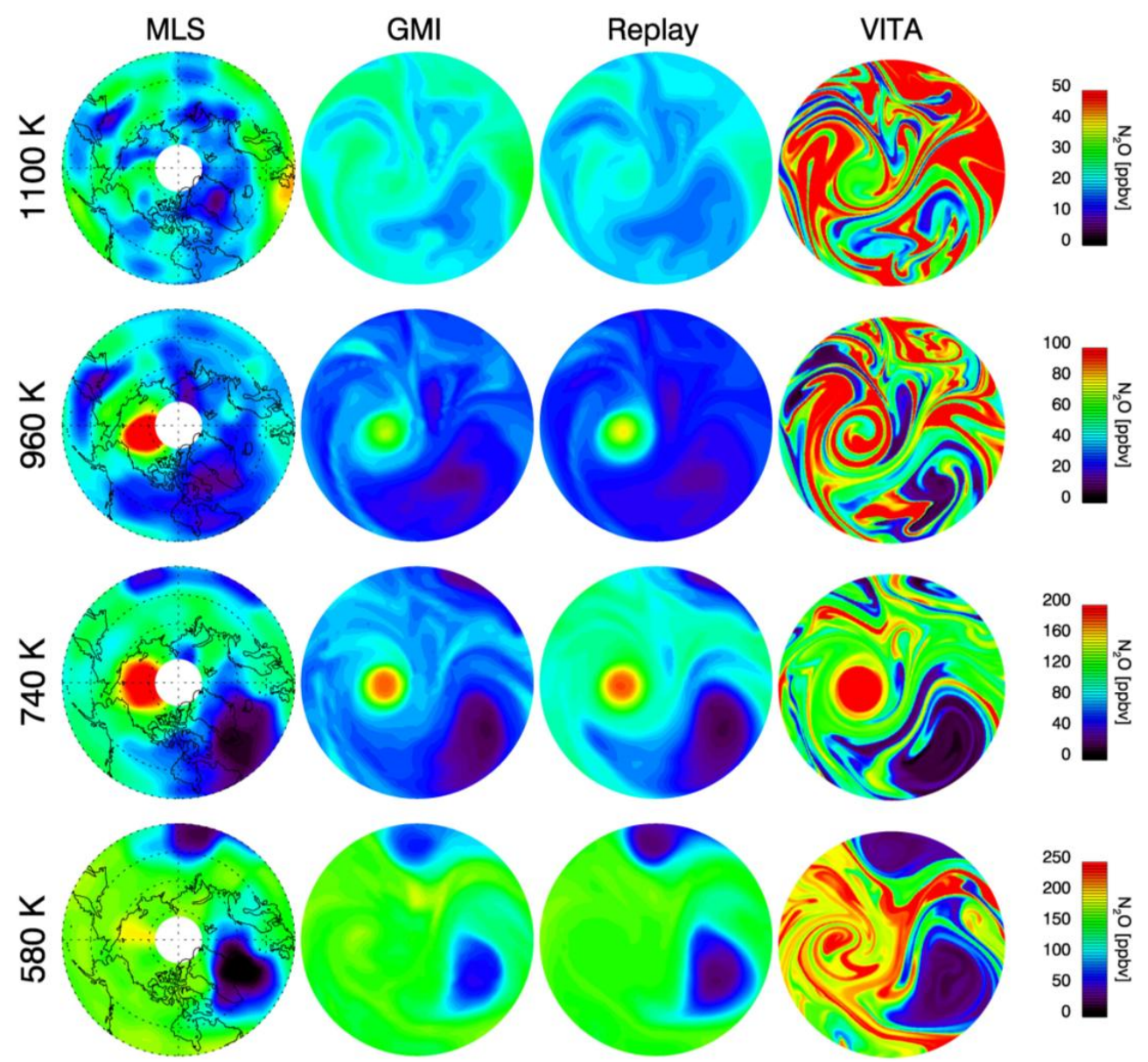

Fig. 7. MLS $\mathrm{N}_{2} \mathrm{O}$ (first column) from $50-90^{\circ} \mathrm{N}$ at several potential temperature levels (rows correspond to 1100,960 , 740, and $580 \mathrm{~K}$ ) for 4 April 2005 along with simulations from GMI (second column), Replay (third column), and VITA (fourth column). Red (blue) indicates high (low) $\mathrm{N}_{2} \mathrm{O}$ values.

This causes the FrIAC to diminish slightly in size, but it is still the dominant feature at high latitudes. The Replay and VITA simulations maintain close correspondence with MLS in terms of the location and size of the FrIAC, albeit with lower maximum values in Replay and more structure in VITA. Aura MLS along-track sections through the FrIAC at $850 \mathrm{~K}$ for 15 May are shown in Fig. 11. The Replay simulation agrees remarkably well with MLS for both tracks, capturing much of the large-scale and fine-scale structure, with exception of the reduced magnitude of the peak. VITA captures the magnitude of the peak, but shows more fine-scale structure than observed in MLS, as expected. There are several valleys and peaks in VITA that do not exist in the MLS data, such as the peak near profile 90 in Orbit 1 and the peaks near profiles 40 and 60 in Orbit 2.

The anticyclonic phase of the FrIAC is marked by both dynamical (local coherent anticyclone and low PV) and chemical (high $\mathrm{N}_{2} \mathrm{O}$ ) signatures. The dynamical properties act to protect the chemical tracer anomaly from the shearing effects of the wind. This is similar to the protective nature of the winter polar vortex remnants that were discussed in Hess and Holton (1985) and Hess (1991). In the case of the 2005 FrIAC the dynamical signature lasted approximately two months, consistent with expected timescales of radiative damping. In the next section we examine the fate of the chemical signature of the FrIAC as it becomes exposed to the shearing effects of the summer vortex.

\subsection{Modeling the Shearing phase: June-August}

The coherent structure of the main body of the FrIAC observed during the anticyclonic phase suggests that the horizontal flow is nearly in solid body rotation (SBR), at least at the high latitudes where the FrIAC develops, in agreement with Piani and Norton (2002). SBR occurs when there is no meridional wind and the zonal wind is proportional to the cosine of latitude $\left(u(\phi)=u_{\text {eq }} \cos (\phi)\right.$, where $u_{\text {eq }}$ is the equatorial wind speed and $\phi$ is latitude). In Fig. 12, the GEOS5 zonal mean wind at $850 \mathrm{~K}$ is plotted for select days from May through August, along with zonal wind for SBR with 

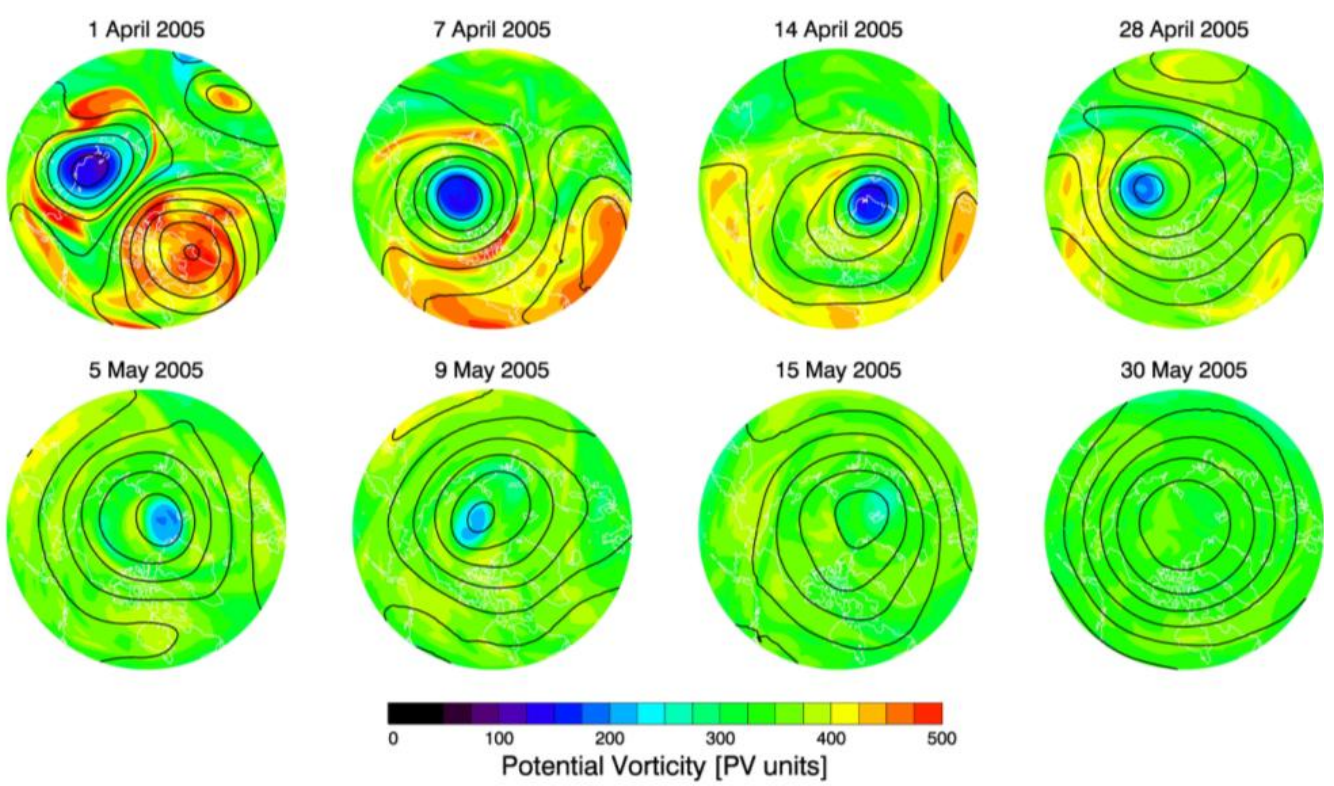

Fig. 8. Ertel potential vorticity at $850 \mathrm{~K}$ potential temperature from $50-90^{\circ} \mathrm{N}$ for $1,7,14$, and 28 April and 5, 9, 15, and $30 \mathrm{May} 2005$. Red (blue) indicates high (low) PV values. Black lines indicate $10 \mathrm{hPa}$ geopotential height at $100-\mathrm{m}$ contour intervals.
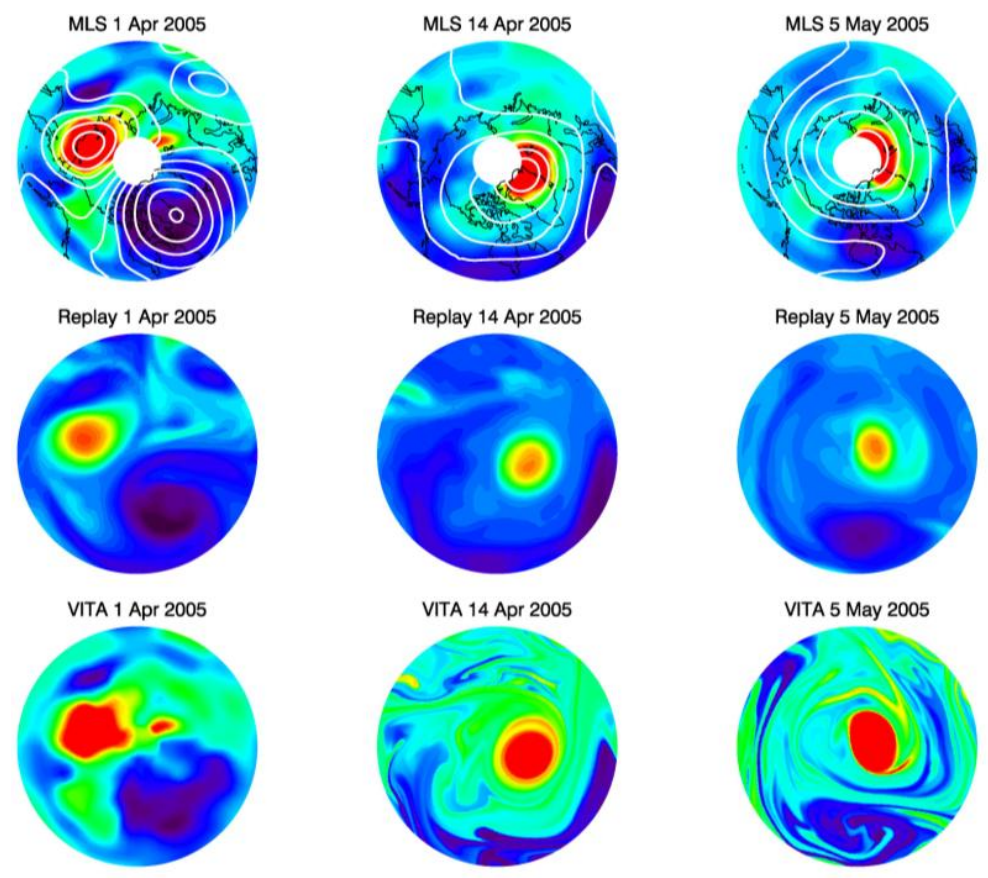

VITA 5 May 2005
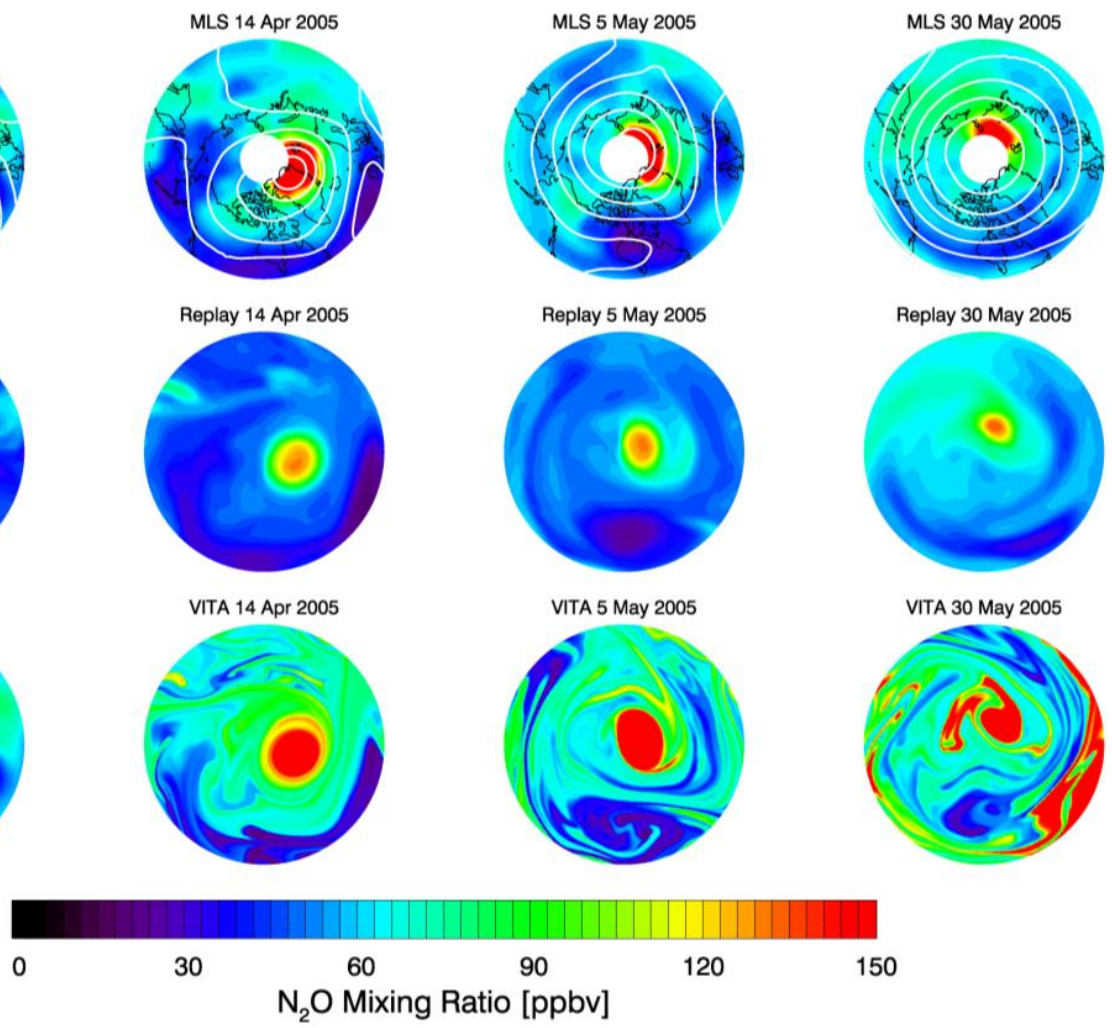

Fig. 9. MLS $\mathrm{N}_{2} \mathrm{O}$ mixing ratio at $850 \mathrm{~K}$ from $50-90^{\circ} \mathrm{N}$ for 1 and 14 April and for 5 and 30 May 2005 overlaid with contours of $10 \mathrm{hPa}$ geopotential height at 100-m intervals (first row). Red (blue) indicates high (low) $\mathrm{N}_{2} \mathrm{O}$ values. Replay $\mathrm{N}_{2} \mathrm{O}$ simulations for the same days (second row). VITA $\mathrm{N}_{2} \mathrm{O}$ simulations initialized on 1 April 2005 (third row). 

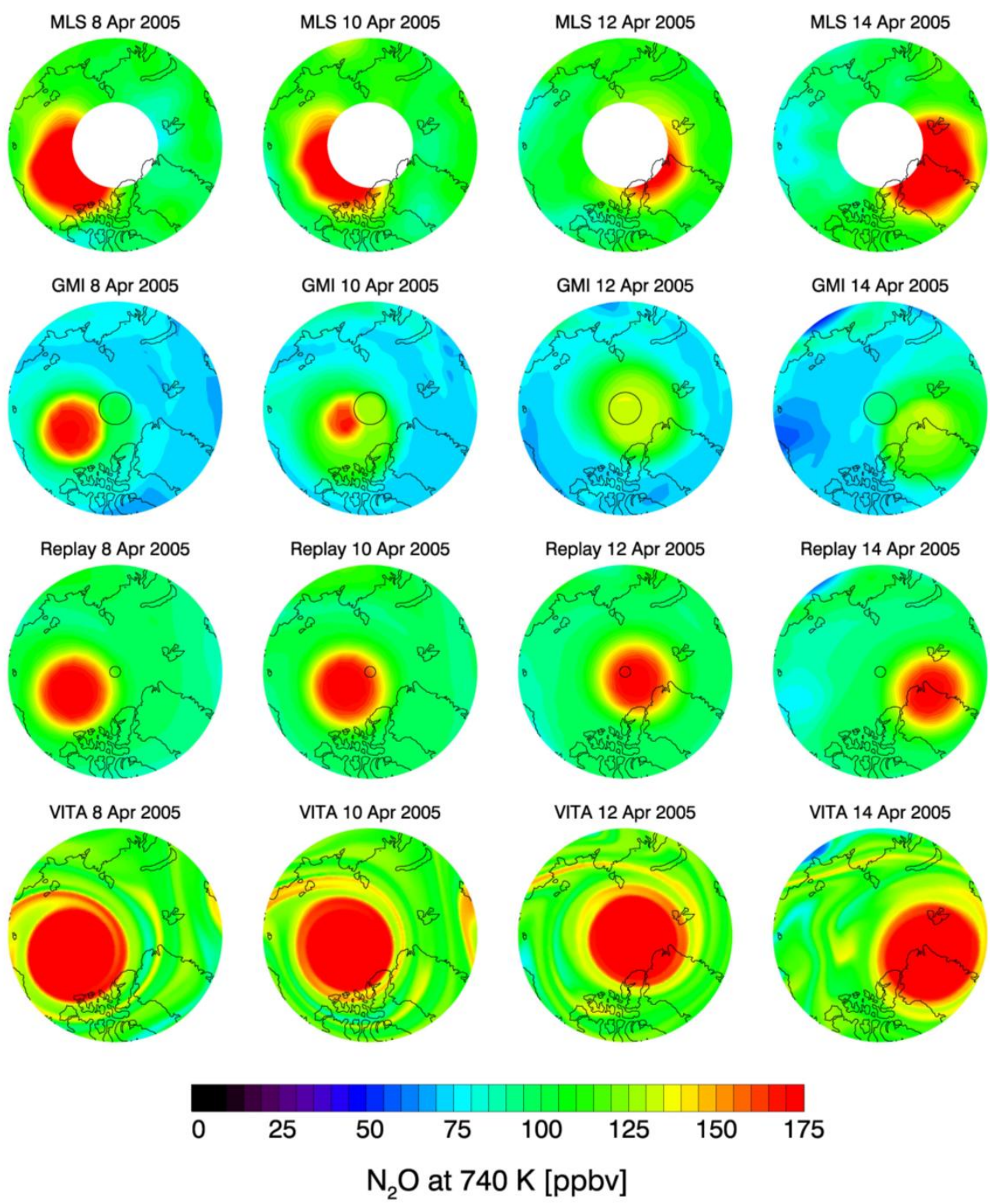

Fig. 10. MLS $\mathrm{N}_{2} \mathrm{O}$ mixing ratio from $70-90^{\circ} \mathrm{N}$ at $740 \mathrm{~K}$ potential temperature for $8,10,12$, and 14 April 2005 along with simulations from GMI, Replay, and VITA. Red (blue) indicates high (low) $\mathrm{N}_{2} \mathrm{O}$ values. Black circles indicate the extent of the polar mixing cap in the GMI and Replay simulations.

different periods of rotation (10, 20,30, 40, and 50 days). In late April (not shown) the flow is approaching SBR at high latitudes, with period of around 10 days (called SBR 10 for short), and on May 10 , the wind is very close to $\mathrm{SBR}_{10}$ from about $75-85^{\circ} \mathrm{N}$, similar to the latitudinal extent of the FrIAC. The flow does not follow SBR equatorward of $70^{\circ} \mathrm{N}$ in late May, consistent with the high- $\mathrm{N}_{2} \mathrm{O}$ streamer that develops (see Fig. 9). During June and July, the rotation more closely follows $\mathrm{SBR}_{20}$ (period of 20 days) from about 65 $90^{\circ} \mathrm{N}$. By August, the flow deviates from SBR with slower winds than required at polar latitudes, suggesting that significant horizontal shearing of the FrIAC will occur in August.
As the winds reverse to westerly the SBR rotation completely breaks down. The wind analyses show that quasi-SBR occurs at high latitudes throughout most of May, June, and July at $850 \mathrm{~K}$, but breaks down completely in mid- to late-August. A high-latitude feature in the tracer field would thus be expected to survive the flow over several months, barring effects of vertical shear (examined in more detail below).

The vertical structure of the FrIAC for MLS and Replay is shown in Fig. 13, which plots the zonal $\mathrm{N}_{2} \mathrm{O}$ anomaly at $74^{\circ} \mathrm{N}$ as a function of longitude and pressure for select days in May and June 2005. On 1 and 22 May the FrIAC (marked by high $\mathrm{N}_{2} \mathrm{O}$ ) is upright, whereas the background 

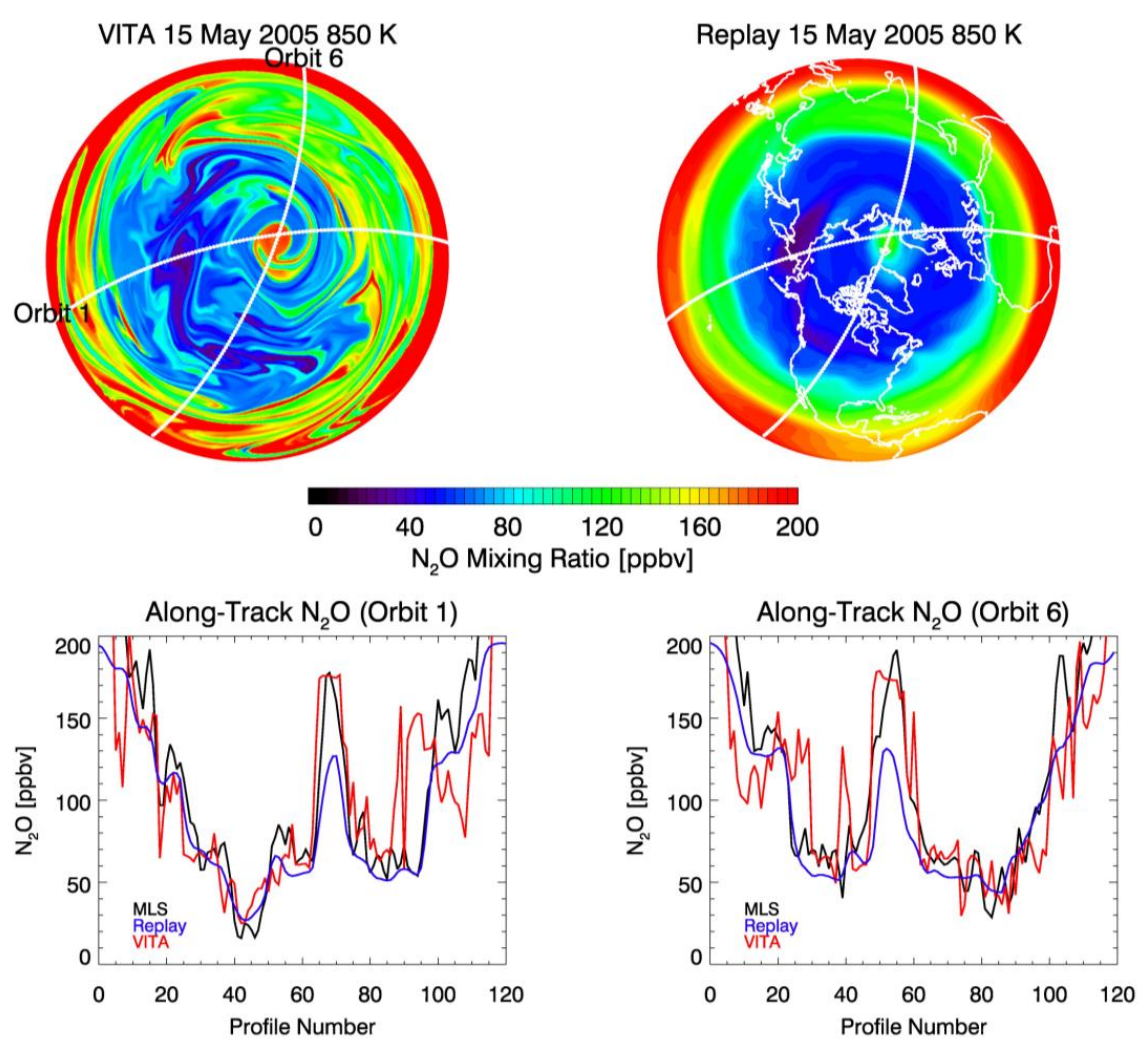

Fig. 11. Top row: Northern Hemisphere VITA (left) and Replay (right) $\mathrm{N}_{2} \mathrm{O}$ at $850 \mathrm{~K}$ on 15 May 2005. Red (blue) indicates high (low) $\mathrm{N}_{2} \mathrm{O}$ values. Overlaid are two EOS Aura MLS orbit tracks for this day. Second row: MLS, Replay, and VITA $\mathrm{N}_{2} \mathrm{O}$ at $850 \mathrm{~K}$ along the selected orbit tracks. The profiles start at the locations of the orbit labels in the upper left panel. Replay and VITA data are interpolated linearly in space and time to the MLS data points.
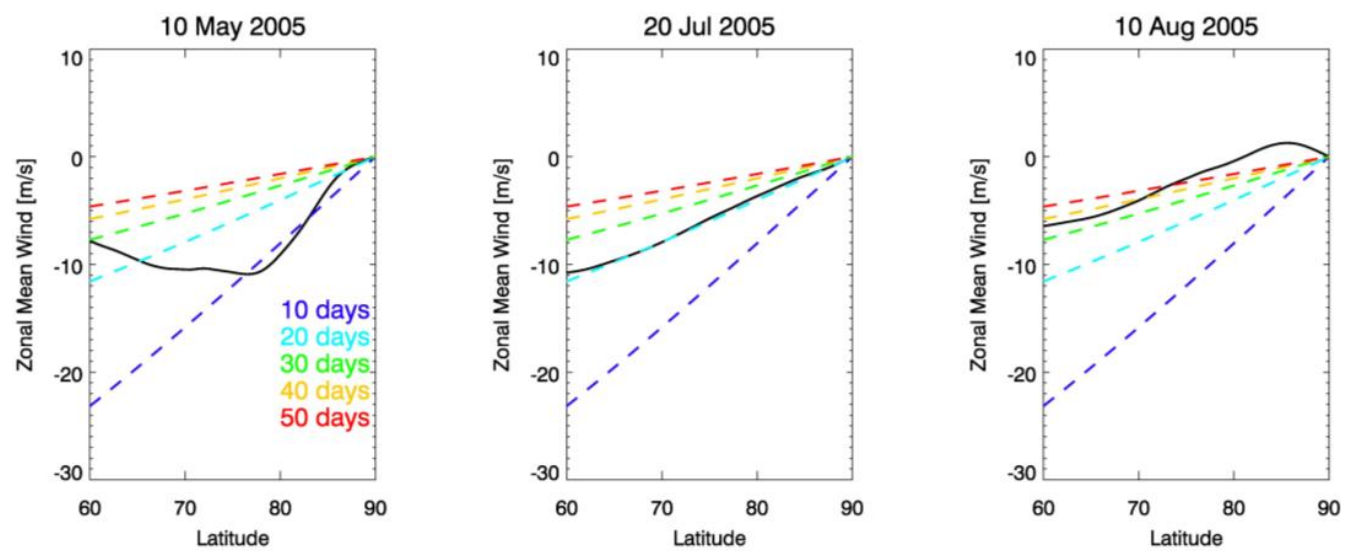

Fig. 12. Zonal mean zonal wind (black line) as a function of latitude at $850 \mathrm{~K}$ for $10 \mathrm{May}, 20 \mathrm{July}$, and 10 August 2005 . Color curves indicate the winds necessary for solid-body rotation with periods of 10 (blue), 20 (cyan), 30 (green), 40 (yellow), and 50 (red) days.

$\mathrm{N}_{2} \mathrm{O}$ contours show significant vertical tilting (westward with height), particularly in Replay. Dynamical studies show that coherent vortices can exhibit resistance to the tilting effects of weak vertical shear. Vandermeirsh and Morel (2002), using a 2 1/2 layer quasigeostrophic model, with separate PV anomalies in each layer, show that the PV anomalies have a self-sustaining advective effect on the other layer that keeps the vortex from splitting in weak shear zones. A more detailed study (Jones, 1995), using primitive-equation numerical modeling of a tropical tropospheric cyclone in vertical 

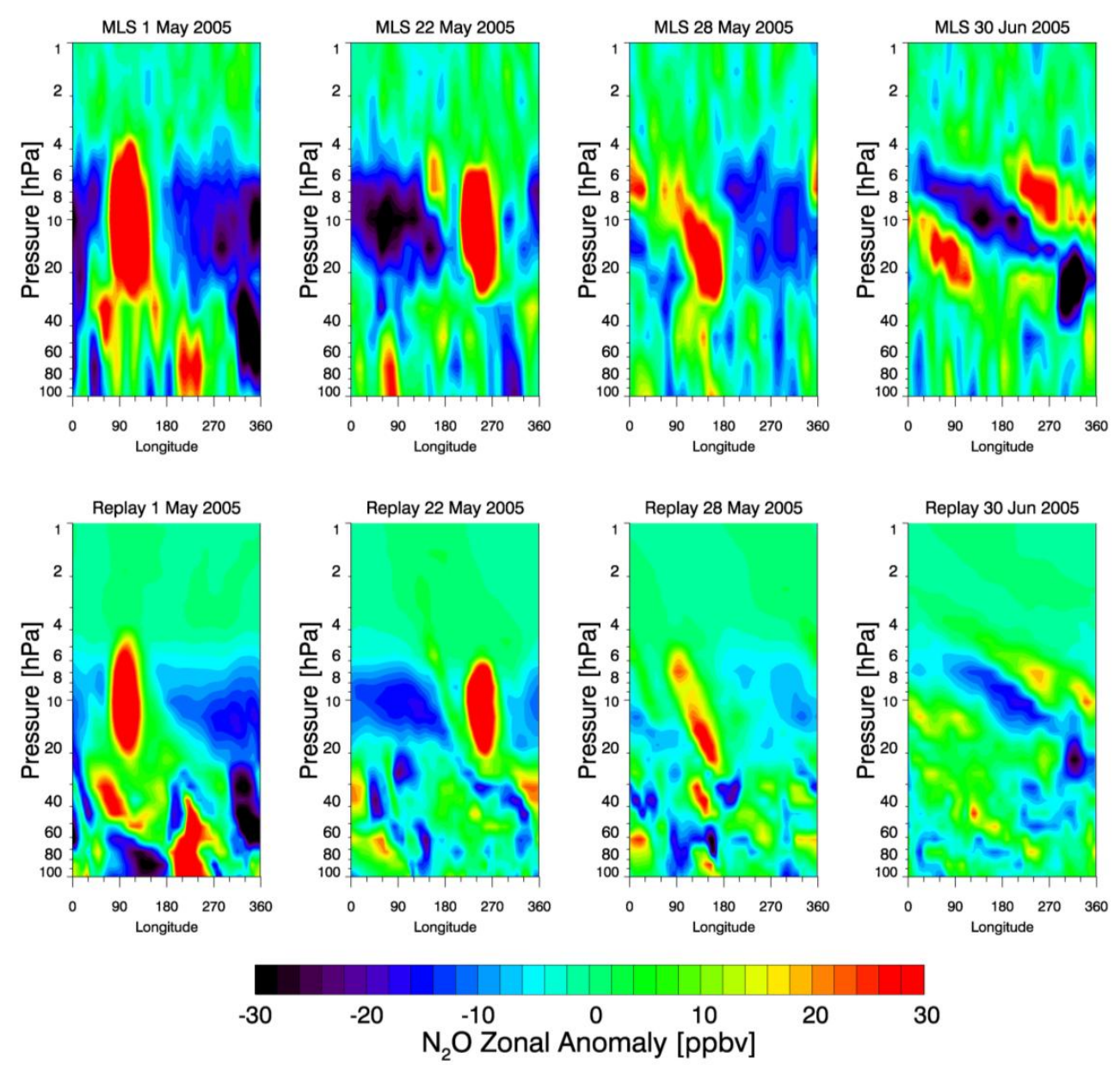

Fig. 13. Longitude vs. pressure cross-sections at $74^{\circ} \mathrm{N}$ latitude of MLS and Replay $\mathrm{N}_{2} \mathrm{O}$ (deviation from zonal mean) for 1,22 , and $28 \mathrm{May}$ and 30 June 2005. Red (blue) indicates high (low) $\mathrm{N}_{2} \mathrm{O}$ zonal anomaly.

shear, shows that upper and lower PV anomalies of an initially barotropic vortex rotate about a common center. The effects of this rotation act to oppose the eroding action of the vertical shear on the vortex. Further work is necessary to elucidate whether these results are consistent with this anticyclonic vortex in the polar stratosphere. As the PV anomaly decays in late May, however, the FrIAC starts tilting and weakening, as observed on 28 May, with even further tilting occurring in June, described in more detail below.

Figure 14 shows the evolution of MLS, Replay, and VITA $\mathrm{N}_{2} \mathrm{O}$ at $850 \mathrm{~K}$ for select days during June-August 2005. VITA was again reinitialized for this period using MLS data on 1 June. In early June, the FrIAC exhibits evidence of horizontal shearing. Whereas on 30 May the main cell of the FrIAC is nearly circular in shape and centered near $80^{\circ} \mathrm{N}$ (see Fig. 9), by 20 June the feature has elongated in the zonal direction due to meridional shear of the zonal wind. Note the long tail that lags behind the main cell of the FrIAC at $180^{\circ} \mathrm{E}$, evident in MLS data and the simulations, wraps completely around the globe. Starting in early July, noticeable differ- ences occur between VITA and MLS data. On 15 July the high $\mathrm{N}_{2} \mathrm{O}$ region in the VITA simulation is spread over 180 degrees of longitude in a rather complicated structure. The MLS data on this date show a single region of high $\mathrm{N}_{2} \mathrm{O}$ near the pole, immersed in background $\mathrm{N}_{2} \mathrm{O}$ levels that are somewhat higher than at midlatitudes. It is unlikely that smoothing of the MLS data can completely account for these differences. To examine this further, Fig. 15 presents along-track plots for 15 July through the large $\mathrm{N}_{2} \mathrm{O}$ anomaly observed in VITA. In Orbit 1 the large anomaly observed in the VITA simulation (profiles 45-60) doesn't have a counterpart in either MLS or Replay. In Orbit 2 there is an anomaly in MLS, but it is observed at a slightly different location.

From 15 July to 30 August, MLS shows the FrIAC to be slowly dissipating (Fig. 14), mixing with the background $\mathrm{N}_{2} \mathrm{O}$ levels. M06 examined SLIMCAT and ReverseTrajectory (RT) simulations of the FrIAC and found that unrealistic shredding of the feature occurred in the simulation, suggesting that the analyzed horizontal winds (UK Met Office in their case) are unrealistically dispersive at high 


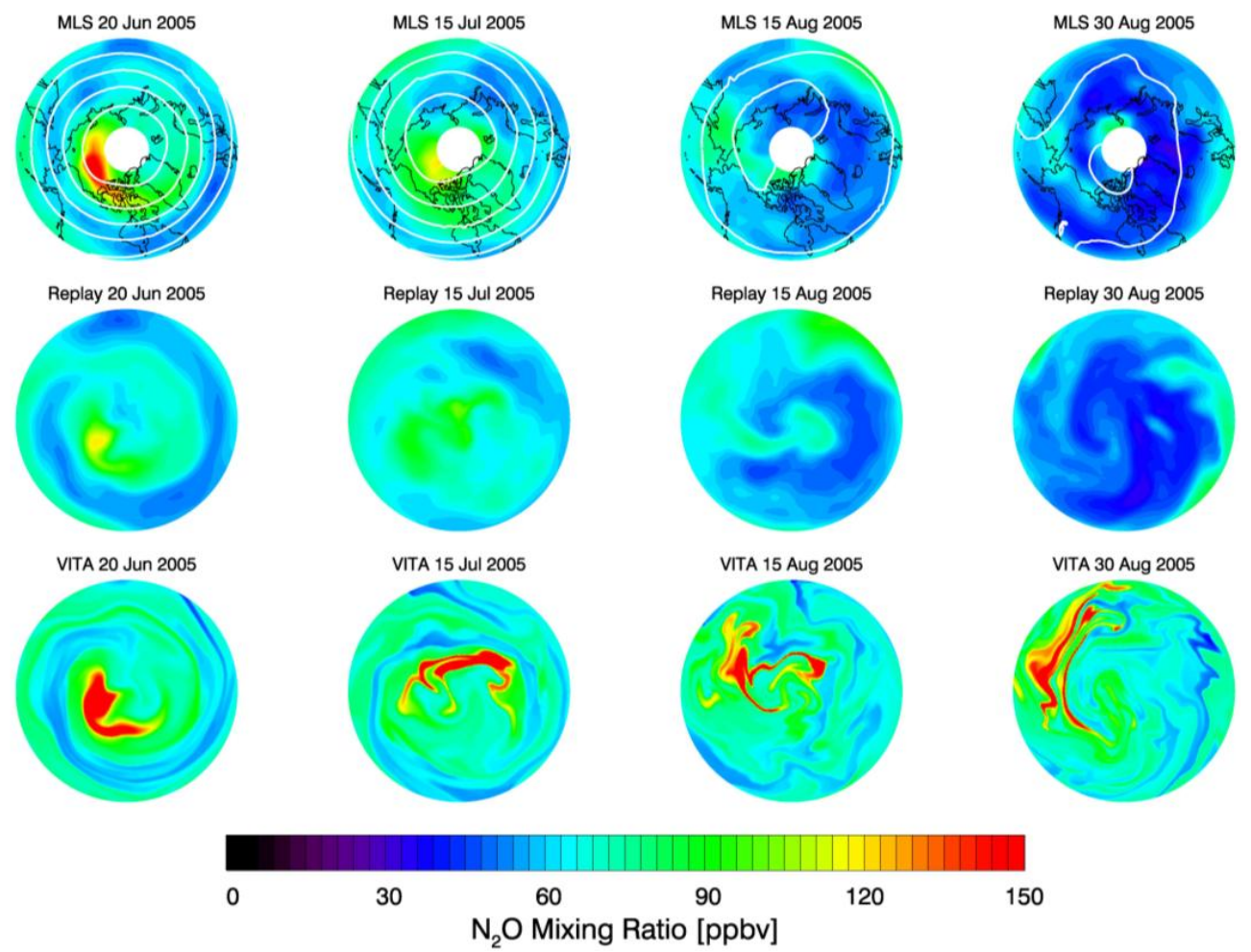

Fig. 14. MLS $\mathrm{N}_{2} \mathrm{O}$ mixing ratio at $850 \mathrm{~K}$ from $50-90^{\circ} \mathrm{N}$ for $20 \mathrm{June}, 15 \mathrm{July}$, and 15 and 30 August 2005 overlaid with contours of $10 \mathrm{hPa}$ geopotential height at 100-m intervals (first row). Red (blue) indicates high (low) $\mathrm{N}_{2} \mathrm{O}$ values. Replay $\mathrm{N}_{2} \mathrm{O}$ simulations for the same days (second row). VITA $\mathrm{N}_{2} \mathrm{O}$ simulations initialized on 1 June 2005 (third row).

latitudes in summer. However, the Replay results show remarkably good agreement with MLS during this third phase, matching the morphology of the $\mathrm{N}_{2} \mathrm{O}$ contours well through at least 15 August. This suggests that the MERRA winds and Replay transport scheme are able to reliably capture the transport of the summer middle stratosphere. Complete mixing of the FrIAC in Replay does not occur until late August, when the feature has all but disappeared in the MLS data as well. Note that the elevated $\mathrm{N}_{2} \mathrm{O}$ observed in MLS data on 30 August near $90^{\circ} \mathrm{E}$ is the final observable remnant of the FrIAC, indicating that complete mixing of the FrIAC may not occur before the winter vortex becomes established in September. That the VITA simulation shows considerable structure in late August suggests that it is largely vertical shear (neglected in VITA) rather than horizontal shear that acts to dissipate the FrIAC. We will attempt to quantify the relative importance of horizontal and vertical shearing effects below.

To summarize performance of the simulations over the entire FrIAC lifecycle, Fig. 16 presents Hovmöller (longitude vs. time) diagrams of the observed and modelled $\mathrm{N}_{2} \mathrm{O}$ at $850 \mathrm{~K}$ and $78^{\circ} \mathrm{N}$ from March-August 2005. The MLS data show that after spin-up the FrIAC makes seven complete cycles around the pole from April to August. The amplitude of the $\mathrm{N}_{2} \mathrm{O}$ anomaly remains relatively undiminished until late July, when the FrIAC apparently develops two maxima around this latitude circle. In August, the westward motion slows significantly, becoming nearly stationary in the latter part of the month. During this time the maximum $\mathrm{N}_{2} \mathrm{O}$ values diminish and the feature mixes into the background. The simulations capture many of the features observed in MLS. The polar-crossings on 7-14 August and 5-9 May are evident in Replay and GMI as temporary disappearances of the $\mathrm{N}_{2} \mathrm{O}$ anomaly at $78^{\circ} \mathrm{N}$, as the feature is poleward of this latitude. The GMI simulation shows sharply diminished peak values during these crossings, leaving a very weak $\mathrm{N}_{2} \mathrm{O}$ anomaly in mid-May. However, following the second polar crossing GMI shows relatively undiminished $\mathrm{N}_{2} \mathrm{O}$ anomaly for four complete cycles. This suggests the analyses and transport schemes are able to maintain the structure of the FrIAC during this period. This is further attested by the Replay simulation, which captures the entire FrIAC lifecycle at this level both qualitatively and quantitatively. Since it is able to resolve the feature during the polar crossings, the $\mathrm{N}_{2} \mathrm{O}$ anomaly is higher in mid-May than in GMI. The anomaly remains undiminished throughout May, June, and July, and even shows a similar splitting into two anomalies in late July, as seen in the MLS data. In August, the Replay continues to capture the anomaly until it diffuses into the background by the end of the month. Replay contours of 75 and $100 \mathrm{ppbv}$ 

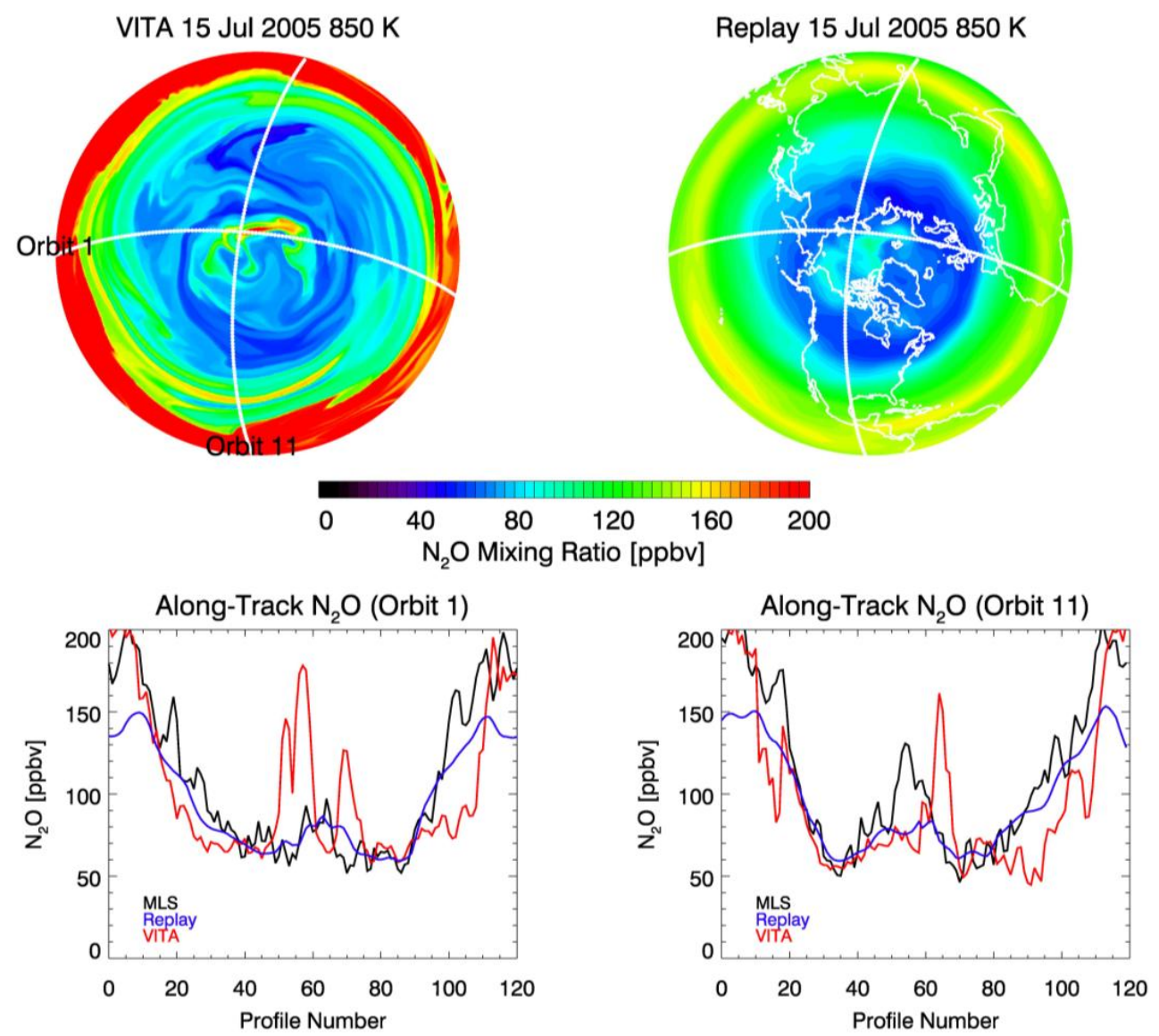

Fig. 15. Top row: Northern Hemisphere VITA (left) and Replay (right) $\mathrm{N}_{2} \mathrm{O}$ at $850 \mathrm{~K}$ on 15 July 2005. Red (blue) indicates high (low) $\mathrm{N}_{2} \mathrm{O}$ values. Overlaid are two EOS Aura MLS orbit tracks for this day. Second row: MLS, Replay, and VITA $\mathrm{N}_{2} \mathrm{O}$ at $850 \mathrm{~K}$ along the selected orbit tracks. The profiles start at the locations of the orbit labels in the upper left panel. Replay and VITA data are interpolated linearly in space and time to the MLS data points.

are overlaid on the MLS contours in Fig. 16 for comparison. As seen by the close correspondence with MLS, Replay performs remarkably well at simulating the evolution and decay of the FrIAC.

The VITA simulation is also shown for comparison. As discussed previously, VITA tends to generate complex structures in the tracer field that last longer than in the MLS observations, due to better horizontal resolution. The Hovmöller plot shown here uses a composite of VITA runs that are initialized on 1 March, 1 April, and 1 June, respectively, in order to reduce the build-up of these features. Even so, more detailed structure occurs in the VITA simulation than seen in the MLS data or the other simulations. Particularly during August, the VITA simulation shows considerable structure. This highlights the fact that vertical processes (neglected in VITA) are necessary for complete modeling of the FrIAC.

That Replay is able to simulate the remnants of the FrIAC well into August implies that the implemented vertical and horizontal resolution is adequate to capture the details of the feature during the shearing phase, at least to the resolution of MLS. Vertical shear during the June-August period causes significant tilting of the tracer structures that decreases the vertical scale and enhances vertical mixing as explained by Haynes and Anglade (1997). To quantify this scale reduction, we employ a simple model to estimate the time for the vertical scale of the FrIAC to reduce to the implemented grid scale ( $\sim 1 \mathrm{~km}$ for Replay). The $\mathrm{N}_{2} \mathrm{O}$ cross-sections in Fig. 13 suggest that we can approximate the FrIAC as a rectangular tracer anomaly with horizontal length (in the zonal direction) $H$ and vertical depth $D$ embedded in a zonal flow with vertical shear (see schematic in Fig. 17). We can calculate the vertical depth $D^{\prime}$ of the anomaly after the top has completely cleared the base by $D^{\prime} / H=D /\left[\left(u_{2}-u_{1}\right) T\right]$, where $T$ is the time elapsed. Using the approximate vertical shear in zonal wind at $75^{\circ} \mathrm{N}$ and $10 \mathrm{hPa}\left(\sim 0.4 \mathrm{~m} \mathrm{~s}^{-1} \mathrm{~km}^{-1}\right.$ or $0.0004 \mathrm{~s}^{-1}$ in late June/early July) and horizontal scale $\sim 2000 \mathrm{~km}$ we obtain a timescale of $\sim 60$ days to reduce the FrIAC to $\sim 1 \mathrm{~km}$. This suggests that GMI should resolve the vertical features of the FrIAC for around two months during the shearing phase, consistent with results presented here. Similar arguments can 

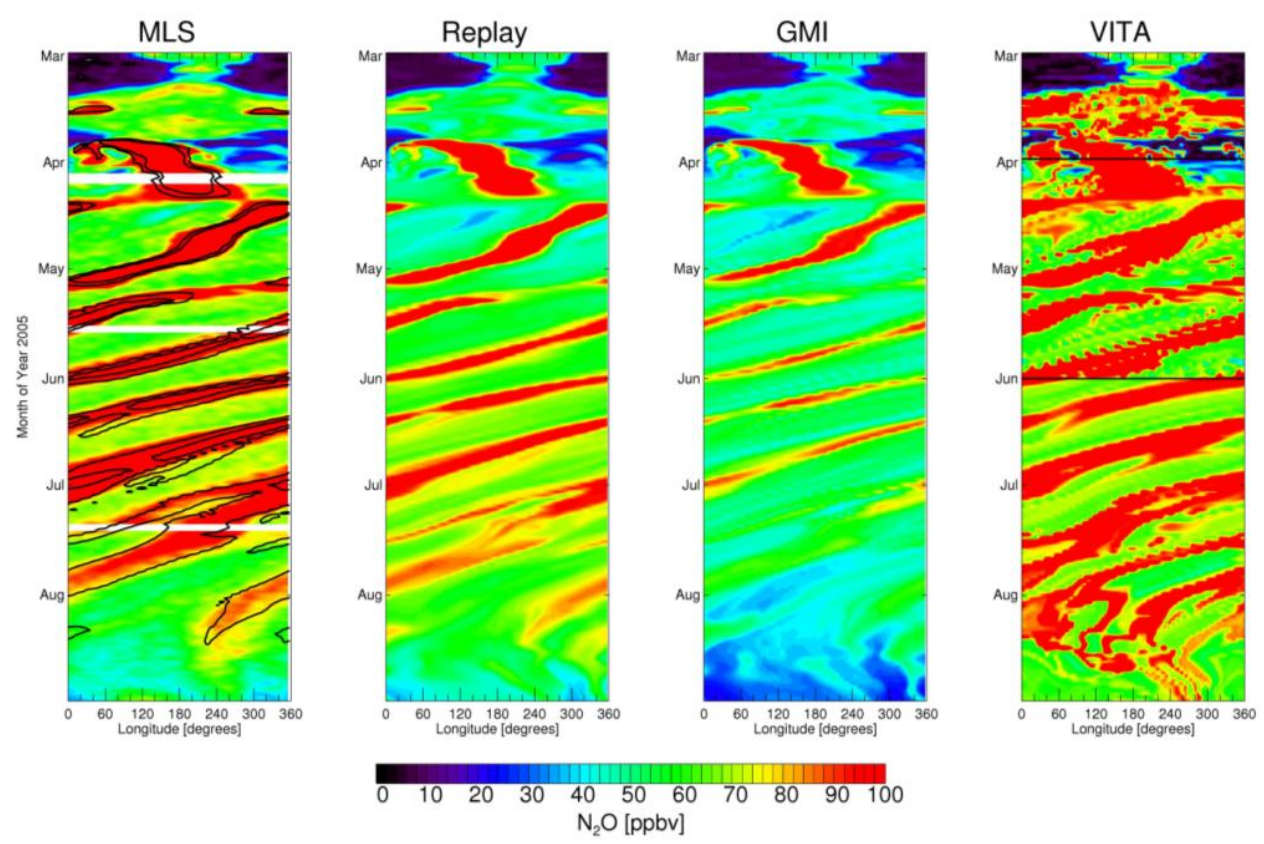

Fig. 16. Longitude vs. time Hovmöller plots of $\mathrm{N}_{2} \mathrm{O}$ at $850 \mathrm{~K}, 78^{\circ} \mathrm{N}$ for MLS, Replay, GMI, and VITA from March to September 2005. Red (blue) indicates high (low) $\mathrm{N}_{2} \mathrm{O}$ values. The black contours on the MLS plot are the 75 and 100 ppbv contours of the Replay simulation, for direct comparison with MLS. White regions on the MLS plot indicate no data available during that time period. The VITA contours are produced from a composite of three runs of the model, initialized with MLS $\mathrm{N}_{2} \mathrm{O}$ on 1 March, 1 April, and 1 June, as indicated by the horizontal black lines.

be used to estimate the timescale for horizontal shear to reduce the lateral scale of the FrIAC to that of the GMI resolution $\left(2^{\circ}\right)$. Using the lateral shear in the zonal wind $\left(\sim 0.5^{\circ}\right.$ longitude $/$ day $/{ }^{\circ}$ latitude in June and July) along with a zonal width of $100^{\circ}$ we estimate that the FrIAC will be resolvable by GMI for $\sim 100$ days. That Replay simulates the horizontal structure of the FrIAC throughout the June-August shearing phase is consistent with these rough estimates.

The FrIAC provides an excellent case study for examining chemical tracer evolution in weak shear flows. Given its coherent nature, it is easy to discriminate air within the FrIAC over the course of five months. The Replay simulates the structure of the FrIAC in $\mathrm{N}_{2} \mathrm{O}$ over its entire lifecycle, at least to the resolution of MLS, attesting both to the assimilated wind fields, the numerical transport, and the simulated $\mathrm{N}_{2} \mathrm{O}$ destruction.

\section{Summary and conclusions}

The general process whereby complicated tracer structures are frozen into the relatively quiescent summer easterly stratospheric flow has been understood for some time. However, detailed observational analysis of long-lived anticyclones such as the 2005 FrIAC over the course of the entire summer depended on the availability of daily hemispheric observations of long-lived tracers such as $\mathrm{N}_{2} \mathrm{O}$ and $\mathrm{H}_{2} \mathrm{O}$.
This study used MLS observations and chemistry and transport simulations to make a detailed analysis of the lifecycle of the FrIAC. The spin-up of the FrIAC occurred when the winter polar vortex was displaced off the pole by the major final warming, causing low latitude air to move northward and merge with the Aleutian high. This process involved two separate episodes that resulted in a coherent anticyclone at very high latitudes, which became enveloped by the summer easterly flow. The anticyclone traversed the pole once in mid-April and once in mid-May before starting a regular westward propagation over the next three months. Until the anticyclone decayed in late May, it protected the FrIAC from vertically shearing. The FrIAC then underwent a regular westward rotation from June-August. Horizontal and vertical shearing in June and July caused the FrIAC to stretch and start to mix with the background air. The FrIAC was finally torn apart in August, although remnants were observed as late as the end of August, when winds became westerly over the entire polar region. Calculations of the shear-induced reduction of vertical and horizontal scales of the FrIAC are consistent with the feature lasting for several months during the shear phase.

Simulations produced using the GMI with GEOS-5 analyses follow the behavior of the FrIAC longer than SLIMCAT simulations presented in M06, but the feature becomes largely indistinguishable by early July. Isentropic simulations using VITA reproduce many aspects of the FrIAC, but 

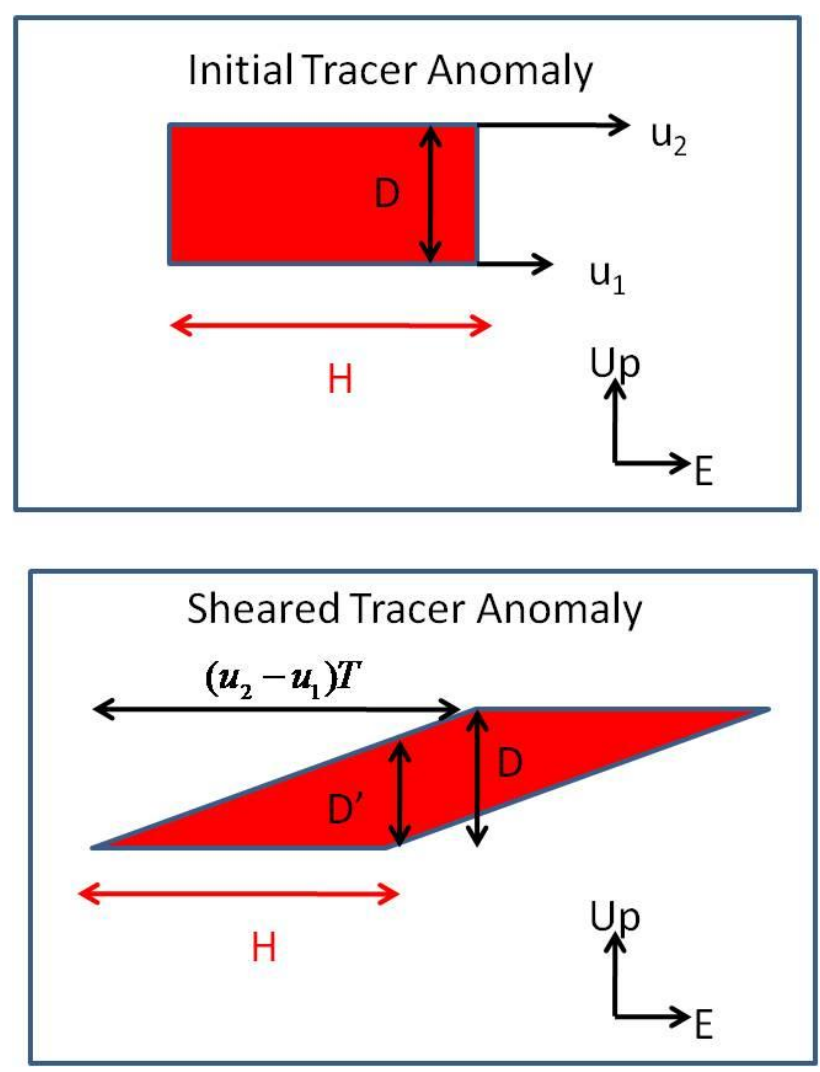

Fig. 17. Schematic diagram of an idealized passive tracer anomaly subject to linear vertical shear of the (steady) zonal wind (east (E) is to the right and Up points vertically upward in both figures). The tracer anomaly initially has a height scale $D$ and width (in the eastwest direction) $H$. The vertical shear is indicated by a difference in zonal wind at the bottom of the anomaly $\left(u_{1}\right)$ and at the top of the anomaly $\left(u_{2}\right)$. The top panel shows the initial tracer anomaly and the bottom panel shows the sheared tracer anomaly at time $T$ after the top of the anomaly has completely passed the base of the anomaly. The vertical thickness of the anomaly is now $D^{\prime}$.

small-scale structures maintained by VITA that are not found in MLS are problematic and show that important mixing processes are absent from this simple single-level simulation. Some improvement in the VITA representation of the FrIAC is gained by periodic re-initialization, suggesting that the information to produce a credible FrIAC simulation is present in the analyses and that GEOS-5 fields themselves do not cause the poor comparisons of MLS observations with GMI. Analysis shows that the comparisons between observations and GMI simulation become markedly worse whenever the FrIAC is transported over the pole.

Results from a simulation with improved horizontal resolution at the pole support this conclusion. The Replay simulation reproduces the important features of the FrIAC, including its August demise. An important difference between the GMI and Replay is the size of the imposed well-mixed polar cap, which introduces artificial diffusion by smoothing the tracer field horizontally across the area of the cap. The large ( $3^{\circ}$ latitude radius) polar cap, used in early implementations to keep the transport code stable when using the noisy assimilated wind fields common to that era, was used in the GMI simulations. The FrIAC horizontal scale is only $\sim 2000 \mathrm{~km}$ compared to the diameter of the polar cap $(660 \mathrm{~km})$, thus any simulation that assumes a well-mixed polar cap of this size cannot maintain a feature the size of the FrIAC if it is transported across the pole, whereas the Replay with $1^{\circ}$ polar cap performed remarkably well. In addition, Replay benefits from a newer version of the flux-form semiLagrangian transport scheme as well as in-line transport that uses the winds at temporal resolution of 30 min rather than $6 \mathrm{~h}$ for GMI. Replay simulated the final mixing processes of the FrIAC well into August, suggesting that the vertical and horizontal resolutions are sufficient to resolve the main aspects of the feature. The success of the Replay is very encouraging with respect to current state-of-the-art models and meteorological analyses.

Acknowledgements. The work was supported by a subcontract of JPL Project-Task 102330-622.56.16 and by the NASA ACMAP Program (NNH09ZDA001N). The authors would like to thank George Nakos for the triangular grid used for the VITA simulations in this study and two anonymous referees for helpful reviews. Work at the Jet Propulsion Laboratory, California Institute of Technology was done under contract with the National Aeronautics and Space Administration.

Edited by: W. Lahoz

\section{References}

Allen, D. J., Douglass, A. R., Rood, R. B., and Guthrie, P. D.: Application of a monotonic upstream-biased transport scheme to three-dimensional constituent transport calculations, Mon. Weather Rev., 119, 2456-2464, 1991.

Allen, D. R. and Nakamura, N.: A seasonal climatology of effective diffusivity in the stratosphere, J. Geophys. Res., 106, 7917-7936, 2001.

Allen, D. R. and Nakamura, N.: Tracer equivalent latitude: A diagnostic tool for isentropic transport studies, J. Atmos. Sci., 60, 287-304, 2003.

Andrews, D. G., Holton, J. R., and Leovy, C. B.: Middle Atmosphere Dynamics, Academic Press, Inc., Orlando, Florida, USA, 268-274, 1987.

Bey, I., Jacob, D. J., Yantosca, R. M., Logan, J. A., Field, B. D., Fiore, A. M., Li, Q., Liu, H. Y., Mickley, L. J., and Schultz, M. G.: Global modeling of tropospheric chemistry with assimilated meteorology: Model description and evaluation, J. Geophys. Res., 106, 23073-23095, 2001.

Bloom, S. C., Takacs, L. L., da Silva, A. M., and Ledvina, D.: Data assimilation using incremental analysis updates, Mon. Weather Rev., 124, 1256-1271, 1996. 
Charney, J. G. and Drazin, P. D.: Propagation of planetary-scale disturbances from lower into upper atmosphere, J. Geophys. Res., 66, 83-109, 1961.

Chipperfield, M. P.: Multiannual simulations with a threedimensional chemical transport model, J. Geophys. Res., 104, 1781-1805, 1999.

Douglass, A. R., Stolarski, R. S., Strahan, S. E., and Connell, P. S.: Radicals and reservoirs in the GMI chemistry and transport model: Comparison to measurements, J. Geophys. Res., 109, D16303, doi:10.1029/2004JD004632, 2004.

Durry, G. and Hauchecorne, A.: Evidence for long-lived polar vortex air in the mid-latitude summer stratosphere from in situ laser diode $\mathrm{CH}_{4}$ and $\mathrm{H}_{2} \mathrm{O}$ measurements, Atmos. Chem. Phys., 5, 1467-1472, doi:10.5194/acp-5-1467-2005, 2005.

Flentje, H. and Kiemle, C.: Erosion and mixing of filaments in the arctic lower stratosphere revealed by airborne lidar measurements, J. Geophys. Res., 108, 4232, doi:10.1029/2002JD002168, 2003

Harvey, V. L., Hitchmann, M. H., Pierce, R. B., and Fairlie, T. D.: Tropical aerosol in the Aleutian high, J. Geophys. Res., 104, 6281-6290, 1999.

Haynes, P. and Anglade, J.: The vertical-scale cascade in atmospheric tracers due to large-scale differential advection, J. Atmos. Sci., 54, 1121-1136, 1997.

Hess, P. G.: Variance in trace constituents following the final stratospheric warming, J. Geophys. Res., 95, 13765-13779, 1990.

Hess, P. G.: Mixing processes following the final stratospheric warming, J. Atmos. Sci., 48, 1625-1641, 1991.

Hess, P. G. and Holton, J. R.: The origin of temporal variance in long-lived tracer constituents in the summer stratosphere, J. Atmos. Sci., 42, 1455-1463, 1985.

Hoppel, K. W., Bowman, K. P., and Bevilacqua, R. M.: Northern Hemisphere summer ozone variability observed by POAM II, Geophys. Res. Lett., 26, 827-830, 1999.

Jones, S. C.: The evolution of vortices in vertical shear. I: Initially barotropic vortices, Q. J. R. Meteorol. Soc., 121, 821-851, 1995.

Lahoz, W. A., Geer, A. J., and Orsolini, Y. J.: Northern hemisphere stratospheric summer from MIPAS observations, Q. J. Roy. Meteorol. Soc., 133, 197-211, 2007.

Lambert, A., Read, W. G., Livesy, N. J., Santee, M. L., Manney, G. L., Frodevaux, L., Wu, D. L., Schwartz, M. J., Pumphrey, H. C., Jimenez, C., Nedoluha, G. E., Cofield, R. E., Cuddy, D. T., Daffer, W. H., Drouin, B. J., Fuller, R. A., Jarnot, R. F., Knosp, B. W., Pickett, H. M., Perun, V. S., Snyder, W. V., Stek, P. C., Thurstans, R. P., Wagner, P. A., Waters, J. W., Jucks, K. W., Toon, G. C., Stachnik, R. A., Bernath, P. F., Boone, C. D., Walker, K. A., Urban, J., Murtagh, D., Elkins, J. W., and Atlas, E.: Validation of the Aura Microwave Limb Sounder middle atmosphere water vapor and nitrous oxide measurements, J. Geophys. Res., 113, D24S36, doi:10.1029/2007JD008724, 2007.

Lin, S.-J. and Rood, R. B.: Multidimensional flux-form semiLagrangian transport schemes, Mon. Weather Rev., 124, 20462070, 1996.

Lin, S.-J.: A Vertically Lagrangian Finite-Volume Dynamical Core for Global Models, Mon. Weather Rev., 132, 2293-2307, 2004.

Manney, G. L., Livesy, N. J., Jimenez, C. J., Pumphrey, H. C., Santee, M. L., MacKenzie, I. A., and Waters, J. W.: EOS Microwave Limb Sounder observations of frozen-in anticyclonic air in Arctic summer, Geophys. Res. Lett., 34, L06810,
doi:10.1029/2005GL025418, 2006.

McIntyre, M. E. and Palmer, T. N.: Breaking planetary-waves in the stratosphere, Nature, 305, 593-600, 1983.

McIntyre, M. E. and Palmer, T. N.: The surf zone in the stratosphere, J. Atmos. Terr. Phys., 46, 825-849, 1984.

Orsolini, Y. J.: Long-lived tracer patterns in the summer polar stratosphere, Geophys. Res. Lett., 28, 3855-3858, 2001.

Pawson, S., Stajner, I., Kawa, S. R., Hayashi, H., Tan, W.W., Nielsen, J. E., Zhu, Z., Chang, L.-P., and Livesey, N. J.: Stratospheric transport using 6-h-averaged winds from a data assimilation system, J. Geophys. Res., 112, D23103, doi:10.1029/2006JD007673, 2007.

Piani, C. and Norton, W. A.: Solid-body rotation in the northern hemisphere summer stratosphere, Geophys. Res. Lett., 29, 2117, doi:10.1029/2002GL016079, 2002.

Putti, M., Yeh, W.-G., and Mulder, W. A.: A triangular finite volume approach with high-resolution upwind terms for the solution of groundwater transport equations, Water Resources Research, 26, 2865-2880, 1990.

Rasch, P., Mahowald, N., and Eaton, B.: Representations of transport, convection, and the hydrologic cycle in chemical transport models: Implications for the modeling of short-lived and soluble species, J. Geophys. Res., 102, 28127-28138, 1997.

Rienecker, M. M., Suarez, M. J., Todling, R., Bacmeister, J., Takacs, L., Liu, H.-C., Gu, W., Sienkiewicz, M., Koster, R. D., Gelaro, R., Stajner, I., and Nielsen, J. E.: The GEOS-5 data assimilation system: Documentation of Versions 5.0.1, 5.1.0, and 5.2.0, NASA Tech. Rep. 104606, Vol. 27, 2008.

Roe, P. L.: Some contributions to the modeling of discontinuous flows, in: Lecture Notes in Applied Mathematics, SpringerVerlag, New York, USA, 22, 163-193, 1985.

Strahan, S. E., Duncan, B. N., and Hoor, P.: Observationally derived transport diagnostics for the lowermost stratosphere and their application to the GMI chemistry and transport model, Atmos. Chem. Phys., 7, 2435-2445, doi:10.5194/acp-7-2435-2007, 2007.

Sweby, P. K.: High resolution schemes using flux limiters for hyperbolic conservation laws, SIAM J. Numer. Anal., 21, 995-1011, 1984.

Vandermeirsh, F., and Morel, Y.: Resistance of a coherent vortex to a vertical shear, J. Phys. Oceanogr., 32, 3089-3100, 2002.

Wagner, R. E. and Bowman, K. P.: Wavebreaking and mixing in the Northern Hemisphere summer stratosphere, J. Geophys. Res., 105, 24799-24807, 2000.

Waters, J. W., Froidevaux, L., Harwood, R. S., Jarnot, R. F., Pickett, H. M., Read, W. G., Siegel, P. H., Cofield, R. E., Filipiak, M. J., Flower, D. A., Holden, J. R., Lau, G. K. K., Livesey, N. J., Manney, G. L., Pumphrey, H. C., Santee, M. L., Wu, D. L., Cuddy, D. T., Lay, R. R., Loo, M. S., Perun, V. S., Schwartz, M. J., Stek, P. C., Thurstans, R. P., Boyles, M. A., Chandra, K. M., Chavez, M. C., Chen, G. S., Chudasama, B. V., Dodge, R., Fuller, R. A., Girard, M. A., Jiang, J. H., Jiang, Y. B., Knosp, B. W., LaBelle, R. C., Lam, J. C., Lee, K. A., Miller, D., Oswald, J. E., Patel, N. C., Pukala, D. M., Quintero, O., Scaff, D. M., Van Snyder, W., Tope, M. C., Wagner, P. A., and Walch, M. J.: The Earth Observing System Microwave Limb Sounder (EOS MLS) on the Aura satellite, IEEE Trans. Geosci. Remote Sens., 44, 1075-1092, 2006.

Waugh, D. W. and Rong, P. P.: Interannual variability in the decay 
of lower stratospheric Arctic vortices, J. Meteorol. Soc. Jpn., 80, 997-1012, 2002.

Williamson, D. L.: The evolution of dynamical cores for global atmospheric models, J. Meteor. Soc. Japan, 85B, 214-269, 2007.
Wu, W.-S., Purser, R. J., and Parish, D. F.: Three-dimensional analyses with spatially inhomogeneous covariances, Mon. Weather Rev., 130, 2905-2916, 2002. 